\title{
Synaptic UNC13A protein variant causes increased neurotransmission and dyskinetic movement disorder
}

\author{
Noa Lipstein, ${ }^{1}$ Nanda M. Verhoeven-Duif,, ${ }^{2,3}$ Francesco E. Michelassi, ${ }^{4}$ Nathaniel Calloway, ${ }^{4}$ Peter M. van Hasselt, ${ }^{5}$ \\ Katarzyna Pienkowska, ${ }^{1}$ Gijs van Haaften, ${ }^{2,3}$ Mieke M. van Haelst, ${ }^{3}$ Ron van Empelen, ${ }^{6}$ Inge Cuppen, ${ }^{7}$ Heleen C. van Teeseling, ${ }^{8}$ \\ Annemieke M.V. Evelein, ${ }^{9}$ Jacob A. Vorstman, ${ }^{9}$ Sven Thoms, ${ }^{10}$ Olaf Jahn, ${ }^{11}$ Karen J. Duran, ${ }^{2,3}$ Glen R. Monroe, ${ }^{2,3}$ Timothy A. Ryan, ${ }^{4}$ \\ Holger Taschenberger, ${ }^{1}$ Jeremy S. Dittman, ${ }^{4}$ Jeong-Seop Rhee, ${ }^{1}$ Gepke Visser, ${ }^{5}$ Judith J. Jans, ${ }^{3}$ and Nils Brose ${ }^{1}$ \\ 'Department of Molecular Neurobiology, Max Planck Institute of Experimental Medicine, Göttingen, Germany. ${ }^{2}$ Center for Molecular Medicine and ${ }^{3}$ Department of Genetics, University Medical Center \\ Utrecht, Utrecht, Netherlands. ${ }^{4}$ Department of Biochemistry, Weill Cornell Medical College, New York, New York, USA. ${ }^{5}$ Department of Pediatric Metabolic Diseases, Wilhelmina Children's Hospital, Utrecht, \\ Netherlands. ${ }^{6}$ Child Development and Exercise Center, Division of Paediatrics, University Medical Center Utrecht, Utrecht, Netherlands. 'Department of Paediatric Neurology, Wilhelmina Children's Hospital, \\ University Medical Center Utrecht, Utrecht, Netherlands. ${ }^{8}$ Department of Paediatric Psychology, Sector of Neuropsychology, and ${ }^{9}$ Brain Center Rudolf Magnus, Department of Psychiatry, University Medical \\ Center Utrecht, Utrecht, Netherlands. ${ }^{10}$ Department of Pediatrics and Pediatric Neurology, University Medical Center, Georg August University, Cöttingen, Germany. ${ }^{11}$ Proteomics Group, Max Planck Institute \\ of Experimental Medicine, Göttingen, Germany.
}

\begin{abstract}
Munc13 proteins are essential regulators of neurotransmitter release at nerve cell synapses. They mediate the priming step that renders synaptic vesicles fusion-competent, and their genetic elimination causes a complete block of synaptic transmission. Here we have described a patient displaying a disorder characterized by a dyskinetic movement disorder, developmental delay, and autism. Using whole-exome sequencing, we have shown that this condition is associated with a rare, de novo Pro814Leu variant in the major human Munc13 paralog UNC13A (also known as Munc13-1). Electrophysiological studies in murine neuronal cultures and functional analyses in Caenorhabditis elegans revealed that the UNC13A variant causes a distinct dominant gain of function that is characterized by increased fusion propensity of synaptic vesicles, which leads to increased initial synaptic vesicle release probability and abnormal short-term synaptic plasticity. Our study underscores the critical importance of fine-tuned presynaptic control in normal brain function. Further, it adds the neuronal Munc13 proteins and the synaptic vesicle priming process that they control to the known etiological mechanisms of psychiatric and neurological synaptopathies.
\end{abstract}

\section{Introduction}

Nerve cell synapses, the key signaling units in the brain, operate with high speed, precision, and fidelity to control all body functions and behavioral outputs. Genetic studies in patient cohorts and analyses of corresponding animal models identify synaptopathies - the aberrations in the structure and function of synapses - as major etiological processes in many psychiatric and neurological disorders. Numerous studies on model animals, often based on disease-related mutations, showed that even minor changes in synaptic function have profound deleterious consequences for brain function. The recognition of disease-relevant synaptopathic malfunctions has triggered substantial interest because many of the underlying processes represent promising targets for therapeutic intervention. In fact, synapses are already key targets of many drugs used to treat symptoms of psychiatric and neurological diseases (1-4).

Synapses operate by release of neurotransmitter from presynaptic compartments and reception of the transmitter by cell

Authorship note: J.J. Jans and N. Brose contributed equally to this work. Conflict of interest: The authors have declared that no conflict of interest exists. Submitted: August 19, 2016; Accepted: December 15, 2016. Reference information: J Clin Invest. 2017;127(3):1005-1018. https://doi.org/10.1172/JCI90259. surface receptors in the postsynaptic compartment. In the presynapse, neurotransmitter-filled synaptic vesicles (SVs) dock at the plasma membrane and become fusion competent in a process called priming. Only primed SVs, which constitute the so-called readily releasable SV pool (RRP), can rapidly fuse with the plasma membrane and release their transmitter content in response to an invading action potential (AP) and the concomitant $\mathrm{Ca}^{2+}$ influx (5, 6). Excitation of the presynaptic membrane by an $\mathrm{AP}, \mathrm{Ca}^{2+}$ influx, and SV fusion are tightly coupled in time and space by the coordinated action of a large number of presynaptic proteins that operate as a multicomponent protein machine.

SV fusion itself is mediated by the SNARE (soluble $N$-ethylmaleimide-sensitive fusion factor [NSF] attachment protein receptor) complex, consisting of the SV protein synaptobrevin 2 and the plasma membrane proteins SNAP25 and syntaxin 1. SV fusion and the upstream related processes, in turn, are supported and controlled by a large number of presynaptic regulatory proteins, several of which have been implicated in synaptopathies. For instance, (a) variants of genes encoding synapsins, which participate in SV mobilization and trafficking, have been linked to autism spectrum disorders (ASDs) and epilepsy (7); (b) variants of the gene encoding the syntaxin regulator Munc18-1 play a key role in intellectual disability (8) and early-onset epileptic encephalopathies (9-12); (c) variants of genes encoding components of the 
$\mathrm{CSP} \alpha / \mathrm{HSP} 70 / \mathrm{SGT}$ chaperone system, which maintains SNAP25 in a functional conformation, and $\alpha$-synuclein, a small SV interactor that controls synaptobrevin 2 , are causally involved in neurodegenerative disorders (13-15); (d) variants of genes encoding the RIM interactor PNKD or the SNAP25 and synaptotagmin interactor PRRT2 lead to dyskinesia (16-18); and (e) a variant of the gene encoding synaptotagmin 1 , the $\mathrm{Ca}^{2+}$ sensor required for evoked, synchronous SV fusion, was recently identified in a patient with motor and cognitive impairments (19). Beyond these examples, genome-wide association studies and analyses of gene copy number variations and of single-nucleotide polymorphisms in patients suggest a link between the dysfunction of presynaptic proteins and multiple neurological and psychiatric disorders (20-24).

In the present study, we identified a patient with a striking abnormal neurological development and ASD who carries a de novo NM_001080421.2:c.2441C > T nucleotide exchange resulting in a p.(Pro814Leu) nonsynonymous variant of the UNC13A (the human ortholog of Munc13-1) protein. Munc13s are essential SV priming proteins $(25,26)$. They regulate the conformation of syntaxin 1 and thereby promote SNARE complex assembly to generate the RRP $(25,27-31)$. Further, during and after periods of synaptic activity at high AP frequency, Munc13s control the replenishment rate of the RRP, which in turn determines the efficacy of ongoing neurotransmission (29, 32-37). Munc13-dependent modulation of neurotransmission is a major determinant of synaptic short-term plasticity (STP), the plastic changes in the strength of synaptic transmission during and after ongoing synaptic activity. STP is of fundamental importance for many brain functions, including neuronal network oscillations, the computation of motor, somatosensory, and auditory inputs, and working memory (38-43).

Of the 3 main neuronal Munc13 paralogs, Munc13-1 is expressed in the vast majority of neurons of the mammalian brain, whereas Munc13-2 (also known as UNC13B) and Munc13-3 (also known as UNC13C) are expressed in complementary parts of the CNS (44). Mice lacking Munc13-1 die at birth because of severe paralysis, and in glutamatergic mouse hippocampal neurons the loss of Munc13-1 leads to an approximately $90 \%$ reduction of the RRP size and consequent approximate $90 \%$ reduction of spontaneous and AP-evoked glutamate release, without an effect on GABAergic neurotransmission (25). Strikingly, the combined loss of Munc13-1 and Munc13-2 leads to a complete elimination of presynaptic function in most forebrain neurons (26) and severely perturbed synaptic transmission at neuromuscular junctions (45). Loss of UNC13A in a recently identified human patient - possibly along with the expression of a dominant-negative protein fragment - was shown to severely perturb neuromuscular synaptic transmission (46), in agreement with the findings in deletion-mutant mice.

We describe here a patient with delayed neurological development, dyskinesia, ASD, and comorbid attention-deficit hyperactivity disorder (ADHD). Using whole-exome sequencing (WES), we identified a de novo variant of UNC13A (UNC13A ${ }^{\mathrm{P} 814 \mathrm{~L}}$ ) in the patient. Electrophysiological analyses in mouse neurons and genetic and behavioral experiments in Caenorhabditis elegans showed that this variant leads to a novel gain of UNC13A/Munc13-1 function, characterized by an increased fusion propensity (fusogenicity) of SVs, and consequently by increased SV release probability $\left(\mathrm{p}_{\mathrm{r}}\right)$, abnormal evoked and spontaneous transmitter release, and perturbed STP.

\section{Results}

Clinical history. The patient, a boy who was 6 years of age at the time of the conclusion of the present study, was born after a pregnancy that was complicated by preeclampsia. Delivery was induced at a gestational age of 37 weeks (Apgar after 1 and 5 minutes, 9 and 10 , respectively; birth weight $2.85 \mathrm{~kg}$ ). There were no apparent in utero, perinatal, or postnatal injuries or infections, and no maternal intoxications during the pregnancy. His Dutch parents are healthy and unrelated (Figure 1A), and have a healthy younger daughter. Standard auditory tests after birth were normal. There is no family history of neurological or neurodevelopmental disability.

Since shortly after birth, the patient has been under surveillance of medical specialists due to a developmental delay. A dyskinetic movement disorder with notable tremors and hyperkinesia became evident soon after birth. This dyskinesia does not resemble generalized dystonia, paroxysmal nonkinesigenic dyskinesia (PNKD), or paroxysmal kinesigenic dyskinesia (PKD). Rather, the patient showed hyperkinesia with continuous movements (Supplemental Video 1; supplemental material available online with this article; https://doi.org/10.1172/JCI90259DS1). The patient was able to roll over at the age of 8 months and walk independently at the age of 2 years. Gradually, his movement pattern normalized, but he still suffers from a continuous form of dyskinesia with intention tremor in his arms that increases during excitement and limits his fine motor skills. The patient's speech development has been severely delayed. From the age of 4 years onward, speech ability progressed rapidly, with the patient speaking 2- to 3-word sentences at the age of 4 years 8 months, and full sentences at the age of 6 years. He was fully toilet-trained at the age of 4 years. At the age of 4 years, the patient suffered from 2 febrile seizures. Family history revealed that the brother of the patient's father also had febrile seizures, but no relatives are known to suffer from epilepsy. EEG revealed a normal differentiated, reactive, and symmetrical pattern appropriate for age, and no seizure activity. We did not observe dysfunction of the immune system in the patient.

The Bayley Scale of Infant Development (BSID-2-NL; refs. $47,48)$ was used to assess the patient's mental development. At 36 months BSID results indicated a developmental age of 17.5 months, which is consistent with a Mental Developmental Index below 55. At the age of 4.8 years, his mental development had progressed to a developmental age equivalent of 27 months. At the age of 6.7 years, he was tested using the Dutch (short) version of the Wechsler Intelligence Scale for Children Nonverbal Scale of Ability (49), indicating a nonverbal IQ of 70. His recognition memory and memory of events are not impaired. Developmental regression was never observed. Currently, the patient attends a special education school for children with intellectual disability (IQ range 50-70). MRI scans at 1,2, and 4 years of age showed a normal aspect of gray and white matter differentiation and normal midline structures. Neither structural abnormalities nor signs of leukodystrophy were seen in the basal ganglia (Supplemental Figure 1). The development of cardiac, respiratory, and immunological functions was normal. Clinical examination showed no dysmorphic features, and the patient's growth parameters have been within the normal range (height at age 6 years, $1.24 \mathrm{~m}$ [-0.17 SD]; weight at age 6 years, $24.5 \mathrm{~kg}$ [weight to length $0.5 \mathrm{SD}$ ]). 
A

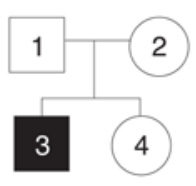

$P$

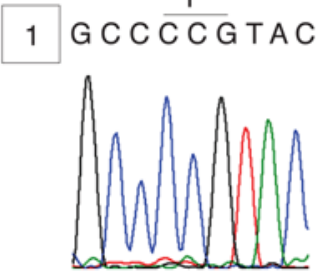

$P$

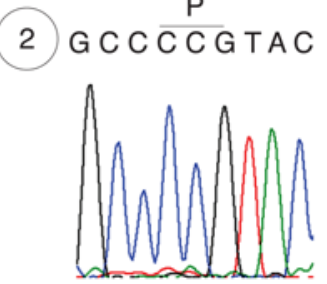

$P / L$

3 GCC $\underset{T}{P C T T A C}$

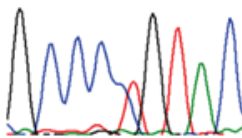

B

MUN domain (neurons)

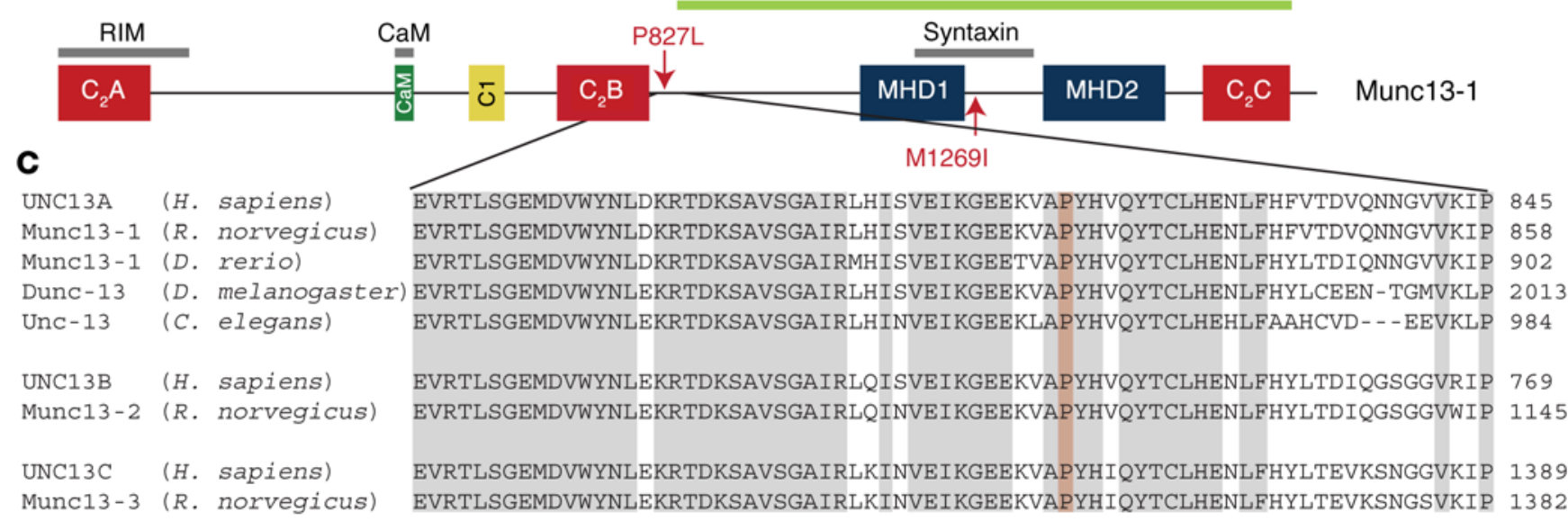

Figure 1. Identification of a single-nucleotide exchange in the UNC13A gene in the patient. (A) Sequence chromatograms demonstrate a single-nucleotide exchange in 1 allele of the UNC13A gene in the patient that is absent in his parents' alleles. (B) Domain structure of Munc13-1. The priming function of Munc13-1 is mediated by a C-terminal MUN domain (green horizontal line), which is composed of 2 Munc13-homology domains (MHD1, MHD2) (88) and the C-terminal C2 domain (C2C) $(54,89)$. This region contains the minimal binding region (gray horizontal line) for syntaxin (90). The central region of Munc13-1 is composed of 3 regulatory domains, a Ca ${ }^{2+}$-calmodulin (CaM) binding domain (33, 35), a C1 domain (63, 91), and the central C2 domain (C2B) (37). The positions of the point mutations that were analyzed in the present study are labeled by red arrows (amino acid positions refer to the murine sequence). The N-terminal C2A domain binds RIM $\alpha$ proteins (68). (C) Amino acid alignment of Munc13 proteins from the indicated organisms shows high sequence identity (gray) in the region covering the mutated proline (red).

The patient showed deficits in social and communicative domains, as well as repetitive behaviors. In addition, a notable short attention span, a high level of distractibility, and hyperactive and impulsive behaviors were observed and evaluated as exceeding what is to be expected given his lower cognitive abilities. Based on clinical evaluation and additional diagnostic tests, the patient met the criteria for ASD and a comorbid ADHD, combined subtype (Supplemental Methods). A trial of methylphenidate was initiated, starting with a single morning dose of $2.5 \mathrm{mg}$ that was slowly titrated to $10 \mathrm{mg}$ twice per day. At this dosage, both school and parents noticed a substantial improvement, particularly of the patient's attention span. The patient was able to remain on task for some time, which allowed him to better engage in learning activities. However, his high level of distractibility remained unchanged. No changes in eating pattern or notable increase in heart rate were observed. Increasing the methylphenidate dosage to $15 \mathrm{mg}$ twice per day did not result in further improvement, and the patient was stabilized on $10 \mathrm{mg}$ twice per day.

Identification of a de novo UNC13A single-nucleotide exchange resulting in a Pro814Leu exchange in human UNC13A. WES of DNA isolated from blood samples of the patient and both parents was performed because trio-WES is currently the best approach for the identification of rare, de novo variants in the offspring. First, we searched for de novo mutations by compar- ing the genome of the patient to those of the parents. A single, heterozygous, de novo variant was identified in UNC13A [NC_ 000019.9:g.17753685G $>$ A (hg19), NM_001080421.2(UNC13A): c.2441C $>$ T, NM_001080421.2(UNC13A_i001):p.(Pro814Leu)] (Figure 1A). No other heterozygous de novo variants were found. An additional analysis was performed to discover rare homozygous variants that are present at a population frequency of less than $0.5 \%$ in 2 large-scale population frequency databases, the Exome Aggregation Consortium (ExAC) (50) and the Genome of the Netherlands (GoNL) (51). These rare variants were then examined on the basis of known gene function and predicted variant effect (Table 1), but none were found to be associated with intellectual disability or with movement disorders, and none could account for the patient's phenotype. The WES data were also used to determine the paternity of the father by assessing variants in the patient that were inherited from the father and not present in the ExAC large-scale variant population frequency database. We therefore concentrated our analysis on the de novo UNC13A variant.

We did not find evidence for the existence of the UNC13A variant in the variation database of the ExAC, which contains exome data of over 60,000 individuals (accessed September 2016), nor in the GoNL database or in our in-house database. The missense variant was confirmed by Sanger sequencing (Figure 1A). It is predicted by the Polymorphism Phenotyping tool (PolyPhen-2; ref. 
Table 1. Rare homozygous variants detected by trio-WES

\begin{tabular}{|c|c|c|c|c|c|c|c|}
\hline HGVS genomic nomenclature & Gene & dbSNP ID & Location & Variation & SIFT & PolyPhen-2 & Interpretation \\
\hline NC_000011.9:g.103124009A>T & DYNC2H1 & - & Intronic & - & - & - & $\begin{array}{l}\text { Intronic variant (NM_001080463.1:c.10064-5A>T) near } \\
\text { a splice site; not likely deleterious; DYNC2H1 homozygous } \\
\text { or compound heterozygous exonic variants cause SRTD3 } \\
\text { (OMIM 613091); no phenotypic similarity } \\
\text { to the disease described here. }\end{array}$ \\
\hline NC_000022.10:g.43036120T>C & ATP5L2 & - & Exonic & $\begin{array}{c}\text { p.Lys54Arg, } \\
\text { nonsynonymous }\end{array}$ & Tolerated & Benign & $\begin{array}{l}\text { Gene function unknown; related to mitochondrial } \\
\text { membrane ATP synthase; not likely explanatory } \\
\text { for patient phenotype. }\end{array}$ \\
\hline NC_000023.10:g.96139748G>T & RPA4 & - & Exonic & $\begin{array}{l}\text { p.Val147Phe, } \\
\text { nonsynonymous }\end{array}$ & Deleterious & $\begin{array}{l}\text { Possibly } \\
\text { damaging }\end{array}$ & $\begin{array}{l}\text { Part of replication protein A ssDNA binding complex; } \\
\text { not expressed in the brain; no link to patient phenotype. }\end{array}$ \\
\hline NC_000023.10:g.100493970G>A & $D R P 2$ & rs146304533 & Exonic & $\begin{array}{c}\text { p.Ala147Thr, } \\
\text { nonsynonymous }\end{array}$ & Tolerated & Benign & $\begin{array}{c}\text { Dystrophin-related protein-2; ExAC contains several } \\
\text { hemizygotes with loss-of-function variants; } \\
\text { not likely explanatory for patient phenotype. }\end{array}$ \\
\hline NC_000023.10:g.131762336G>A & HS6ST2 & - & Exonic & $\begin{array}{l}\text { p.Pro618Leu, } \\
\text { nonsynonymous }\end{array}$ & Tolerated & Benign & $\begin{array}{l}\text { Heparan sulfate 6-0-sulfotransferase 2; involved in cell } \\
\text { proliferation and migration; not likely explanatory } \\
\text { for patient phenotype. }\end{array}$ \\
\hline
\end{tabular}

Rare homozygous variants detected by trio-WES. Homozygous variants (population frequency less than $0.5 \%$ in the ExAC and GoNL databases) were examined based on known gene function and predicted variant effect. The data on PSC size, RRP, and release probability for Figure 5 refer to the subset of experiments in which RRP depletion in response to application of 500 mM and 250 mM sucrose was assayed in a comparative manner. HGVS, Human Genome Variation Society; PolyPhen-2, Polymorphism Phenotyping tool (52); SIFT, Sorting Intolerant From Tolerant algorithm (53); SRTD3, short-rib thoracic dysplasia 3 with or without polydactyly.

52) to be possibly damaging, and by the Sorting Intolerant From Tolerant (SIFT; ref. 53) algorithm to be deleterious. Sequence alignment showed that the proline (P827 in rat Munc13-1; Figure 1, $\mathrm{B}$ and $\mathrm{C}$ ) is evolutionarily conserved from C. elegans UNC-13 to the human UNC13s, and present in all Munc13 paralogs (Figure 1C). However, the functional role of the affected sequence is unknown.

The Pro-Leu exchange in Munc13-1 increases initial synaptic strength. To study the effects of the human $\mathrm{UNC} 13 \mathrm{~A}^{\mathrm{P} 814 \mathrm{~L}}$ variation on neurotransmission, we used autaptic neuronal cultures, where single neurons grow on small astrocyte islands, so that a neuron makes synapses only onto itself. This well-established culture system allows for highly standardized experiments and has been extensively used for analyses of structure-function relationships in synaptic proteins $(25,26,29,35,54-58)$. We used autaptic hippocampal excitatory/ glutamatergic and striatal inhibitory/GABAergic neurons obtained from Munc13-1 Munc13-2 double knockout (DKO) mouse brains. In these neurons, no spontaneous or AP-evoked SV fusion is detectable. We introduced the corresponding Pro827Leu exchange in the murine Munc13-1 cDNA and generated lentiviral particles encoding C-terminally EGFP-fused Munc13-1 ${ }^{\mathrm{WT}}$ or Munc13-1 ${ }^{\mathrm{P} 827 \mathrm{~L}}$ (note that Munc13-1-EGFP fusion proteins are functionally identical to the respective untagged variants; refs. 29, 32-37). Subsequently, autaptic DKO neurons were infected with these lentiviral particles, and the phenotypic rescue effect of the re-expression of Munc13-1 ${ }^{\mathrm{WT}}$ or of Munc13-1 ${ }^{\mathrm{P} 827 \mathrm{~L}}$ was examined by patch-clamp recordings of spontaneous and AP-evoked synaptic activity $(26,59)$.

First, infected neurons were whole-cell voltage-clamped, and evoked excitatory or inhibitory postsynaptic currents (EPSCs and IPSCs) (Figure 2A) were recorded in response to a 2-ms depolarization step to $0 \mathrm{mV}$, which elicits a single escaping AP in the axon. DKO neurons rescued with Munc13-1 ${ }^{\mathrm{P} 827 \mathrm{~L}}$ exhibited approximately $40 \%$ larger EPSC amplitudes on average $(P<0.01)$ and slightly larger IPSC amplitudes $(P>0.05)$ than neurons rescued with Munc13- $1^{\text {WT }}$ (Figure 2, A and B, and Table 2). We did not observe a difference in the kinetics of evoked postsynaptic currents (PSCs) as assessed by measurement of the PSC half-width $(P>0.05$ for both EPSCs and IPSCs; Table 2). To evaluate synaptic transmission under more physiological conditions, we elevated the recording temperature from approximately $22^{\circ} \mathrm{C}$ (room temperature) to $35^{\circ} \mathrm{C}-37^{\circ} \mathrm{C}$, and changed the composition of the extracellular solution to contain $2 \mathrm{mM} \mathrm{Ca}^{2+}$ and $1 \mathrm{mM} \mathrm{Mg}^{2+}$. Under these conditions, hippocampal neurons expressing Munc13-1 ${ }^{\mathrm{P} 827 \mathrm{~L}}$ showed EPSC amplitudes that were on average about twice as large as the EPSC amplitudes in Munc13-1 ${ }^{\mathrm{WT}}$-expressing neurons $(P<0.01)$ (Figure 2, C and D, and Table 2), with no significant difference in the halfwidth of evoked EPSCs ( $P>0.05$; Table 2$)$.

Using C. elegans as a model, we next tested whether the Pro814Leu exchange in human UNC13A has a deleterious effect when introduced at the organism level and in the presence of the WT isoform. This model organism was chosen because the molecular machineries of C. elegans, mouse, and also human presynapses are strikingly similar, and many of the relevant proteins, including UNC13A, were actually first discovered in C. elegans (60). Based on sequence homology (Figure 2E), we identified Pro956 in the C. elegans UNC-13L protein as homologous to human Pro814 in UNC13A and murine Pro827 in Munc13-1. We generated transgenic worm lines that express the mutated UNC-13 [UNC-13L(P/L)] in (a) the background of the unc-13 KO mutant s69 [unc-13(-)] or (b) the WT background. As controls we used (c) the WT strain, (d) a transgenic line that expresses the WT protein [UNC-13L(WT)] in the $u n c-13(-)$ background, and (e) a transgenic line that expresses the UNC-13L(WT) in the WT strain.

We tested these worm lines for sensitivity to the cholinesterase inhibitor aldicarb (1 mM). Exposure to this drug delays the 
A

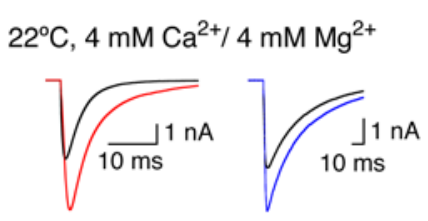

B

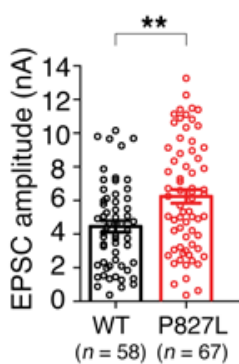

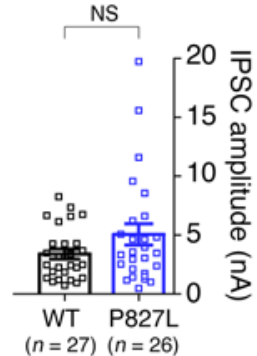

C $37^{\circ} \mathrm{C}, 2 \mathrm{mM} \mathrm{Ca}^{2+} / 1 \mathrm{mM} \mathrm{Mg}^{2+}$ $\sqrt{\frac{\mathrm{b}^{2} \mathrm{nA}}{10 \mathrm{~ms}}}$
E

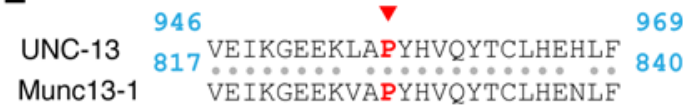

D

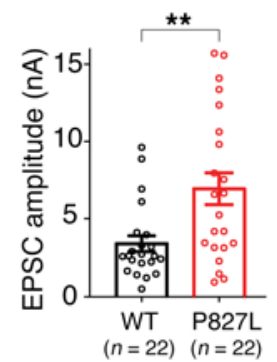

$\mathbf{F}$

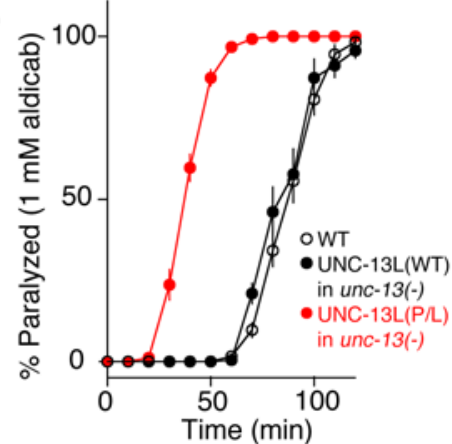

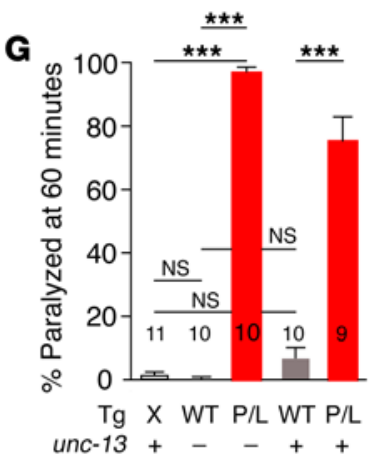

Figure 2. Munc13-1 ${ }^{\text {P227L }}$ increases synaptic strength. (A) Example traces of initial, evoked excitatory postsynaptic currents (EPSCs) from autaptic hip-

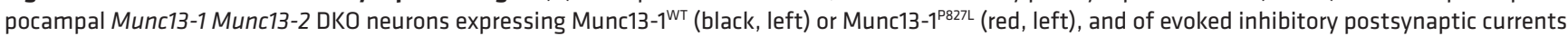

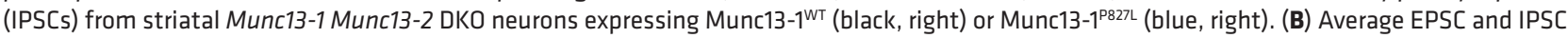
amplitudes as in A. Individual average values per neuron are indicated as circles (left: hippocampal neurons; black, Munc13-1'WT; red, Munc13-1 ${ }^{\text {P227L, }}$ $P<0.01$ ) or squares (right: striatal neurons; black, Munc13-1WT; blue, Munc13-1 ${ }^{\text {P827L }}, P>0.05$ ); Mann-Whitney test. (C) Example traces of EPSCs in hip-

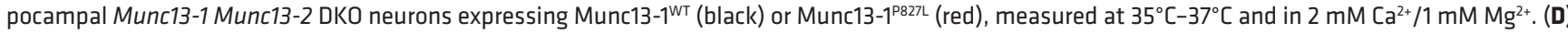
Average EPSC amplitudes as in C. Individual average values per neuron are indicated as circles; $P<0.01$; Mann-Whitney test. (E) Amino acid sequence alignment of murine Munc13-1 and of C. elegans UNC-13L. Red letters indicate Pro827 in Munc13-1 and Pro956 in UNC-13. (F and G) Plot depicting the percentage of WT (open circles, $n=11$ ) and transgenic worms [black circles, UNC-13L(WT) in unc-13(-), $n=10$; red circles, UNC-13L(P/L) in unc-13(-), $n=10$ ] paralyzed as a function of the time following exposure to $1 \mathrm{mM}$ aldicarb (F), and quantification of the percentage of worms paralyzed after 60 minutes of exposure to $1 \mathrm{mM}$ aldicarb (C). Neuronal transgenes (Tg) are WT UNC-13L [UNC-13L(WT)], UNC-13L(P/L), and no transgene (X). Genetic background is indicated as WT (+) or unc-13(s69) null mutant (-), $n=10-11, P<0.01$; ANOVA statistics and Tukey-Kramer test for multiple comparisons. All error bars in the figure represent mean \pm SEM. ${ }^{* *} P<0.01,{ }^{* *} P<0.001$; NS, $P>0.05$. See Table 2 for further details.

degradation of the neurotransmitter acetylcholine, which then accumulates in the synaptic cleft of the neuromuscular junction during synaptic activity, leading to paralysis. Accordingly, a large body of literature on numerous $C$. elegans mutants demonstrates that mutations that enhance presynaptic secretion reduce the time until paralysis is seen, while mutations that cause a reduction or elimination of presynaptic function have the opposite effect (61). The average time to reach paralysis was significantly shorter for worms expressing the UNC-13L $(\mathrm{P} / \mathrm{L})$ mutant in $u n c-13(-)$ as compared with animals expressing UNC-13L(WT) in unc-13(-) (Figure 2, F and G). These findings indicate hypersecretion of acetylcholine in the presence of UNC-13L $(\mathrm{P} / \mathrm{L})$, which is in agreement with the results obtained in our electrophysiological recordings (Figure 2, A-D). In addition, the time to paralysis in mutant worms expressing the UNC-13L $(\mathrm{P} / \mathrm{L})$ mutant on the WT background was significantly shorter than that in WT animals overexpressing UNC-13L(WT) (Figure 2G), indicating that UNC-13L(P/L) has a dominant gain-of-function effect.

Based on the data described in this section, we conclude that the Pro814Leu variant in UNC13A causes a gain of function that does not compromise the function of Munc13-1, but rather exerts a dominant, positive effect on synaptic transmission, even in the presence of the WT protein. The corresponding variant leads to increased synaptic strength in hippocampal and striatal neurons of the mouse CNS and in cholinergic neurons forming the C. elegans neuromuscular junction, indicating a high evolutionary conserva- tion of UNC13/Munc13/UNC-13 function, and high similarity of the phenotypic changes caused by the Pro-Leu exchange.

The Pro-Leu exchange in Munc13-1 increases initial synaptic strength by increasing synaptic release probability. Synaptic strength can increase because of an increase in the number of primed SVs (i.e., RRP size), in the SV quantal size (i.e., in the neurotransmitter content of SVs), or in the probability that an SV is released ( $\left.\mathrm{p}_{\mathrm{r}}\right)$. We therefore tested in autaptic cultured neurons which of these parameters are altered by the murine Munc13-1 $1^{\mathrm{P} 22 \mathrm{~L}}$ exchange. We evaluated the size of the RRP by applying a hypertonic sucrose solution (500 mM for 7 seconds), which releases the entire RRP in a $\mathrm{Ca}^{2+}$-independent manner (62). No significant differences were detected between neurons expressing Munc13-1 ${ }^{\mathrm{WT}}$ and those expressing Munc13-1 $1^{\mathrm{P} 22 \mathrm{~L} \mathrm{~L}}$ (excitatory neurons, $P>0.05$; inhibitory neurons, $P>0.05$; Figure $3, \mathrm{~A}-\mathrm{C}$, and Table 2 ).

We next calculated the vesicular release probability $\mathrm{p}_{\mathrm{vr}}$, which represents the fraction of the RRP released by a single AP (62), and found that the average $\mathrm{p}_{\mathrm{vr}}$ is about $50 \%$ higher in neurons expressing Munc13-1 ${ }^{\mathrm{P} 827 \mathrm{~L}}$ compared with neurons expressing Munc13-1 ${ }^{\mathrm{WT}}$ (excitatory neurons, $P<0.001$; inhibitory neurons, $P<0.01$; Figure 3D and Table 2).

Next, we evaluated the frequency and amplitude of miniature excitatory and inhibitory PSCs (mEPSCs and mIPSCs), which result from spontaneous, AP-independent fusion events of single SVs. The frequencies of mEPSCs and mIPSCs recorded in neurons expressing Munc13-1 1 $827 \mathrm{~L}$ were strongly elevated (mEPSC fre- 
Table 2. Characteristics of synaptic transmission

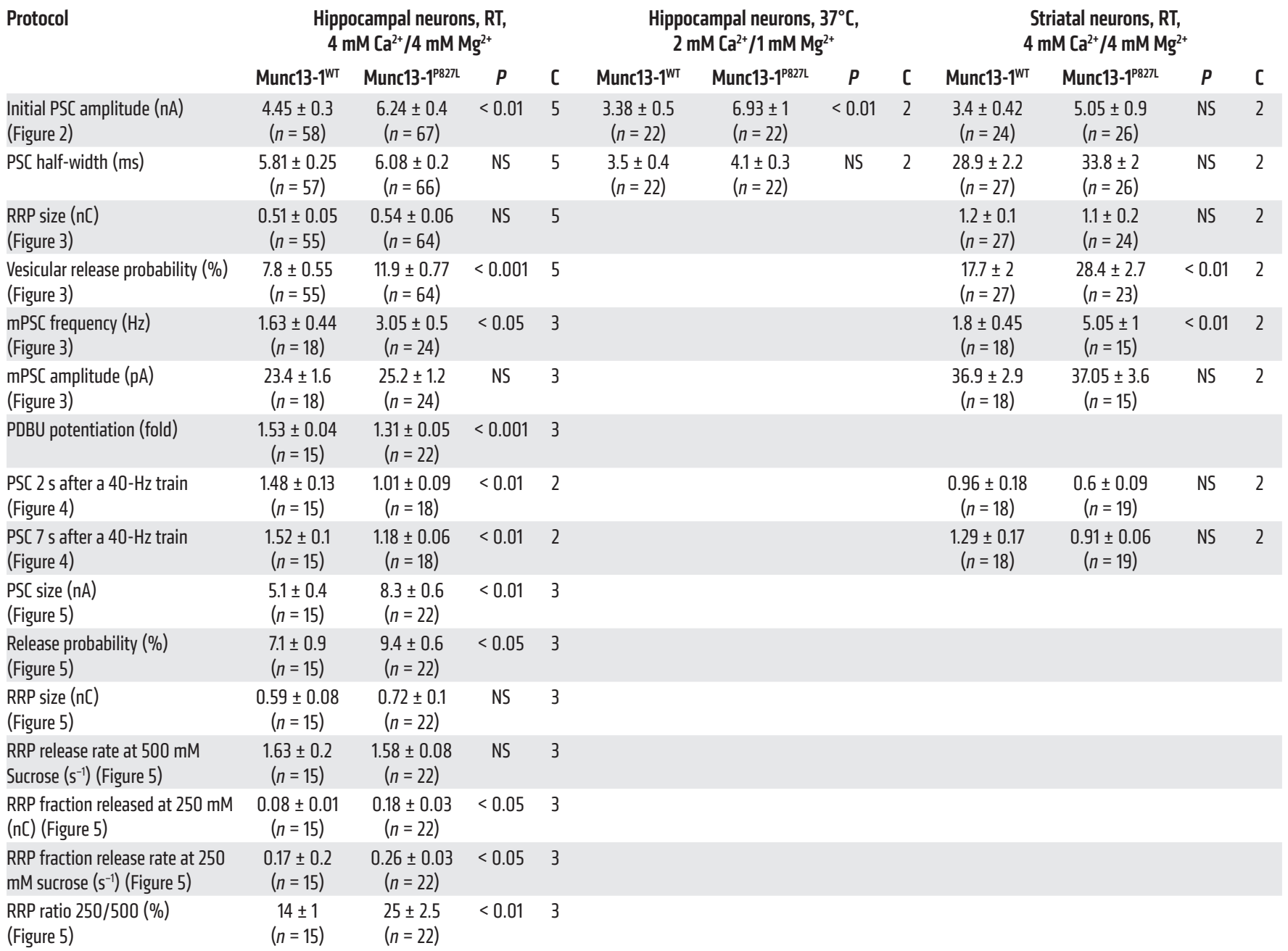

Empty cells, not determined. NS, $P>0.05$. C, number of cultures; RT, room temperature.

quency, $P<0.05$; mIPSC frequency, $P<0.01$; Figure $3, \mathrm{E}-\mathrm{G}$, and Table 2), which is consistent with a higher basal $\mathrm{p}$. Average amplitudes of mEPSCs and mIPSCs were similar for neurons expressing Munc13-1 ${ }^{\mathrm{WT}}$ or Munc13-1 ${ }^{\mathrm{P} 827 \mathrm{~L}}$, excluding the possibility that an increased quantal size contributes to the increase in synaptic strength by Munc13-1 $1^{\mathrm{P} 827 \mathrm{~L}}(P>0.05$ for both mEPSC and mIPSC amplitude; Figure $3 \mathrm{H}$ and Table 2).

In a subsequent set of experiments, we tested the response of synapses to application of the diacylglycerol analog phorbol dibutyrate (PDBU, $1 \mu \mathrm{M})$. Application of PDBU leads to a rapid ( $<5$ seconds) augmentation of the evoked EPSC amplitude, due to an increase in $\mathrm{p}_{\mathrm{r}}$ that is mediated by direct activation of Munc13 proteins (32, $36,63,64)$ and by PKC-mediated phosphorylation of Munc18-1 $(64,65)$ and synaptotagmin $1(66)$. The PDBU augmentation ratio of hippocampal neurons expressing Munc13-1 ${ }^{\mathrm{WT}}$ was significantly higher than that measured for neurons expressing Munc13-1 ${ }^{\mathrm{P} 227 \mathrm{~L}}$ $(P<0.001,5$ seconds after PDBU application; Table 2$)$. Given that $\mathrm{p}_{\mathrm{r}}$ cannot increase indefinitely, the reduced, relative PDBU-mediated augmentation of EPSCs in cells expressing Munc13-1 ${ }^{\mathrm{P} 227 \mathrm{~L}}$ is indicative of an already increased basal $\mathrm{p}_{\mathrm{r}}$ (see Figure 3D).
In summary, the data presented in this section show that the increased EPSC amplitudes caused by the Pro-Leu exchange in Munc13-1 result from an elevated $\mathrm{p}_{\mathrm{r}}$ and not from changes in quantal size or RRP size.

The increased $p_{r}$ caused by the Pro-Leu exchange in Munc13-1 leads to changes in short-term synaptic plasticity. Neurons with high initial $\mathrm{p}_{\mathrm{r}}$ tend to respond to repetitive stimulation at high frequency with short-term depression, i.e., a gradual decrease in synaptic transmitter release. In contrast, neurons with low initial $\mathrm{p}_{\mathrm{r}}$ typically exhibit less depression or even short-term enhancement, i.e., a gradual increase in synaptic transmitter release. In view of the increased $\mathrm{p}_{\mathrm{r}}$ in neurons expressing Munc13-1 $1^{\mathrm{P} 22 \mathrm{~L}}$ (Figure 3D), we next tested the response of hippocampal excitatory and striatal inhibitory neurons expressing Munc13-1 ${ }^{\mathrm{WT}}$ or Munc13-1 ${ }^{\mathrm{P} 82 \mathrm{LL}}$ to AP trains $(2.5 \mathrm{~Hz}$ to $40 \mathrm{~Hz})$. At all frequencies tested, excitatory and inhibitory neurons expressing Munc13-1 ${ }^{\mathrm{P} 22 \mathrm{~L}}$ showed faster depression time course and stronger steady-state depression than neurons expressing Munc13-1 ${ }^{\text {WT }}$ (Figure 4, A-J). Such behavior is consistent with a higher initial $\mathrm{p}_{\mathrm{r}}$ of neurons expressing Munc13-1 ${ }^{\mathrm{P} 827 \mathrm{~L}}$ (Figure 3D), and is further corroborated by the lower paired-pulse 
A
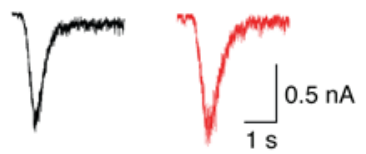

B
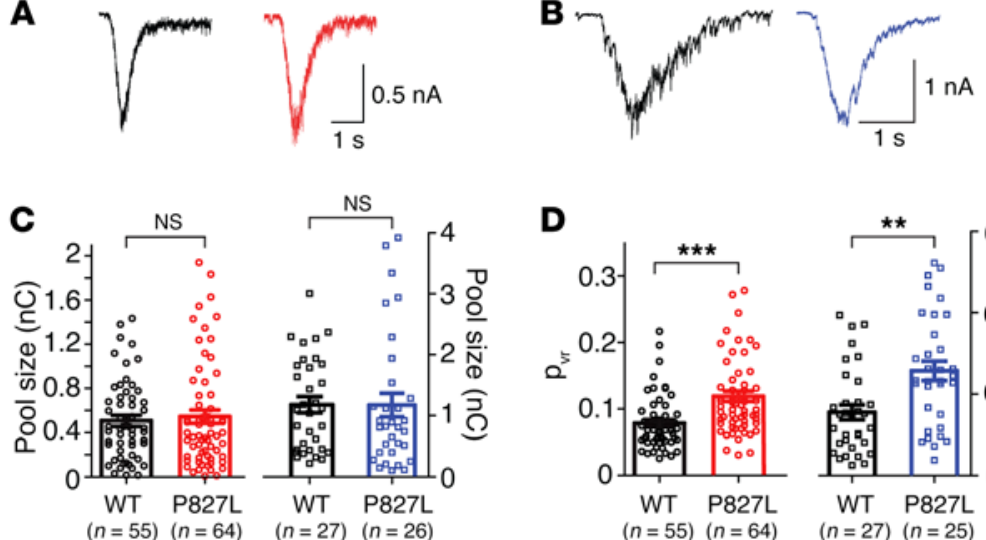

E
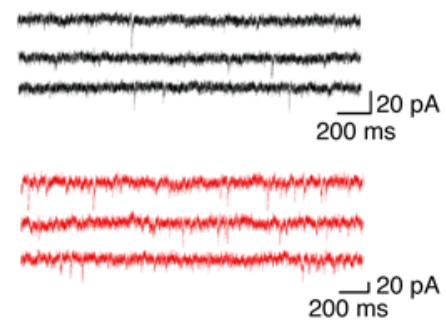

D
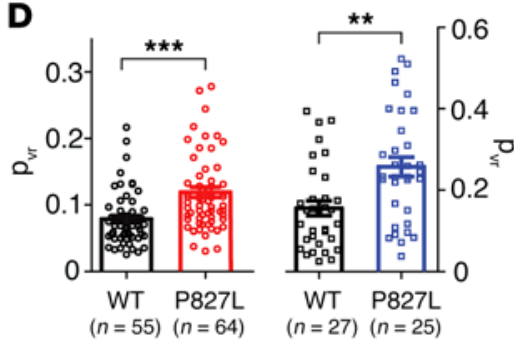

F
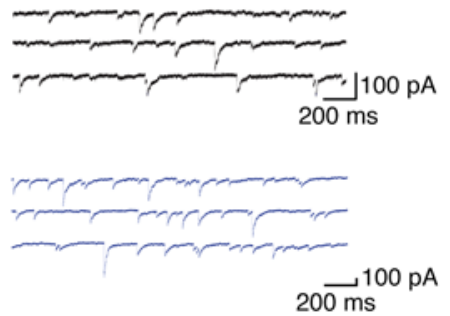

H

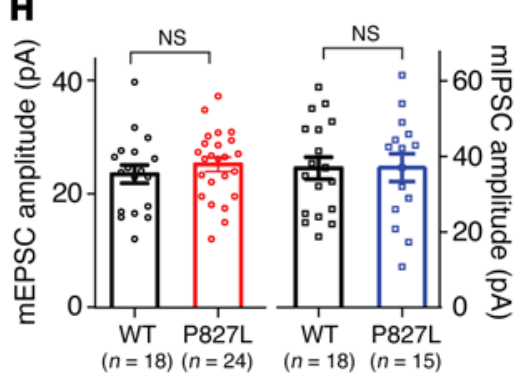

Figure 3. Munc13-1 ${ }^{\text {P827L }}$ increases vesicular release probability. (A and B) Example traces recorded in autaptic hippocampal (A) and striatal neurons (B) from Munc13-1 Munc13-2 DKO neurons expressing Munc13-1 ${ }^{\text {WT }}$ (black) or Munc13-1 ${ }^{\text {P827L }}$ (red/blue) during the application of $500 \mathrm{mM}$ sucrose, representing the release of the RRP of SVs. (C) Plot depicting the average RRP sizes (in $\mathrm{nC}$ ) of all neurons recorded. Individual values per neuron are indicated as circles (left: hippocampal neurons; black, Munc13-1 ${ }^{\mathrm{WT}}$; red, Munc13-1 ${ }^{\text {P827L }}$ ) or squares (right: striatal neurons; black, Munc13-1'TT; blue, Munc13-1 $\left.{ }^{\text {P827L }}\right), P>0.05$; Mann-Whitney test. (D) Plot depicting the average release probability $\left(p_{\mathrm{vr}}\right)$ calculated for each neuron by division of the EPSC charge by the RRP charge. Individual values per neuron are indicated as circles (left: hippocampal neurons; black, Munc13-1 ${ }^{\mathrm{WT}}$; red, Munc13-1 ${ }^{\text {P827L }}, P<0.001$ ) or squares (right: striatal neurons; black, Munc13-1WT; blue, Munc13-1 ${ }^{\text {P827L, }}$ $P<0.01$ ); Mann-Whitney test. (E and $\mathbf{F}$ ) Example traces of mEPSCs (E) and mIPSCs (F) from autaptic hippocampal Munc13-1 Munc13-2 DKO neurons expressing Munc13-1 ${ }^{\text {wT }}$

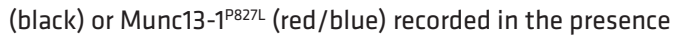
of $300 \mathrm{nM}$ tetrodotoxin. (G) Plot depicting the average mEPSC and mIPSC frequencies. Individual values per neuron are indicated as circles (left: hippocampal neurons; black, Munc13-1 ${ }^{W T}$; red, Munc13-1 ${ }^{\text {P827L }}, P<0.05$ ) or squares (right: striatal neurons; black, Munc13-1'WT; blue, Munc13-1 ${ }^{\text {P827L }}, P<0.01$ ); Mann-Whitney test. (H) Plot depicting the average mEPSC and mIPSC amplitudes. Individual values per neuron are indicated as circles (left: hippocampal neurons; black, Munc13-1 ${ }^{W T}$; red, Munc13-1 $1^{\text {P827L }}, P>0.05$ ) or squares (right: striatal neurons; black, Munc13-1'wT; blue, Munc13-1 ${ }^{\text {P827L }}, P>0.05$ ); MannWhitney test. All error bars in the figure represent mean \pm SEM. ${ }^{*} P<0.05,{ }^{* *} P<0.01,{ }^{* *} P<0.001$; NS, $P>0.05$. See Table 2 for further details. ratios in neurons expressing Munc13-1 ${ }^{\mathrm{P} 827 \mathrm{~L}}$, quantified as the ratio of the second PSC amplitude over the first PSC amplitude in the train (Figure 4, K-M).

Stimulation with high-frequency $(40 \mathrm{~Hz})$ AP trains leads to very low steady-state PSC amplitudes, indicating an almost complete RRP exhaustion (Figure 4, I and J). In DKO neurons expressing Munc13-1 ${ }^{\mathrm{WT}}$, synaptic depression is typically followed by augmentation of transmitter release after the AP train, indicated by elevated PSC amplitudes (Figure 4, I and J, arrowheads). This augmentation was strongly reduced in neurons expressing Munc13-1 $1^{\mathrm{P} 827 \mathrm{~L}}$ (2 seconds after the train: excitatory neurons, $P<0.01$, inhibitory neurons, $P>0.05 ; 7$ seconds after the train: excitatory neurons, $P<0.01$, inhibitory neurons, $P>0.05$; Figure 4 , I and J, and Table 2). Reduced augmentation after an RRP-depleting stimulus may result from a slower Munc13-1-dependent RRP refilling rate, such that the RRP is still partially depleted after the stimulation. Alternatively, $\mathrm{p}_{\mathrm{r}}$ is increased following a train of APs, and reduced augmentation may result from a weaker increase in $\mathrm{p}_{\mathrm{r}}$. To better distinguish between these 2 possibilities, we analyzed the EPSC data obtained with $40-\mathrm{Hz}$ stimulus trains in more detail using a release model that assumes a simple kinetic scheme consisting of a single SV pool that is consumed with a unitary rate of exocytosis and replenished with a fixed replenishment rate constant $\alpha$ (ref. 67 and Supple- mental Figure 2). Fitting such a kinetic model to our EPSC data independently confirmed our previous observation, that neurons expressing Munc13-1 ${ }^{\mathrm{P} 827 \mathrm{~L}}$ exhibit a higher initial $\mathrm{p}_{\mathrm{r}}$ (Supplemental Figure 2D) with no apparent change in the estimated RRP size (Supplemental Figure 2C). Moreover, this analysis predicts that the rate constant $\alpha$ of SV replenishment is unchanged (Supplemental Figure 2E), indicating that a slower RRP refilling rate is unlikely to account for the reduced augmentation following the 40-Hz train. It remains possible that in neurons expressing Munc13-1 ${ }^{\mathrm{P} 827 \mathrm{~L}}$, the high initial $\mathrm{p}_{\mathrm{r}}$ occludes the strong $\mathrm{p}_{\mathrm{r}}$ increase, and consequently the strong PSC augmentation after high-frequency trains of APs.

In summary, the data described in this section indicate that the Pro-Leu exchange we discovered causes profound alterations in synaptic STP, which are likely caused primarily by an effect of the protein variant on $\mathrm{p}_{\mathrm{r}}$ rather than on $\mathrm{RRP}$ size or on the RRP replenishment rate. These changes may have functional consequences for brain processes that depend on STP, such as working memory (42).

The increased $p_{r}$ caused by the Pro-Leu exchange in Munc13-1 results from an increased $S V$ fusogenicity. The data presented above, particularly the combination of normal RRP size, normal $\mathrm{RRP}$ replenishment rate, and increased basal $\mathrm{p}_{\mathrm{r}}$ in the presence of Munc13-1 ${ }^{\mathrm{P} 227 \mathrm{~L}}$ (Figure 3, A-D), indicate that the Pro-Leu variant does not alter the basal SV priming activity of Munc13-1, but 
A $\quad 10 \mathrm{~Hz}$, excitatory neurons Munc13-1 ${ }^{\mathrm{WT}}$

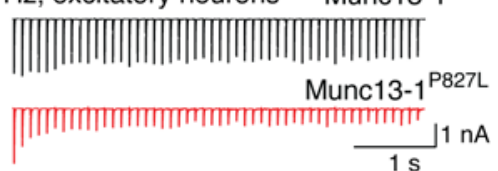

C

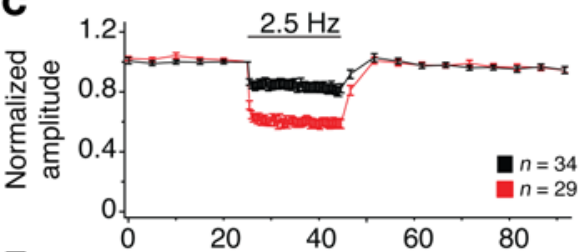

E

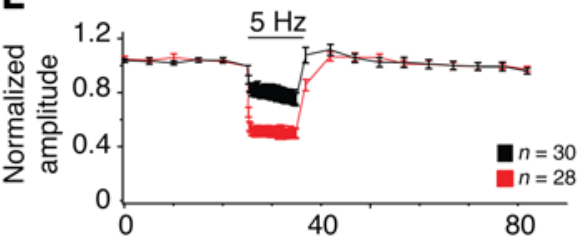

G
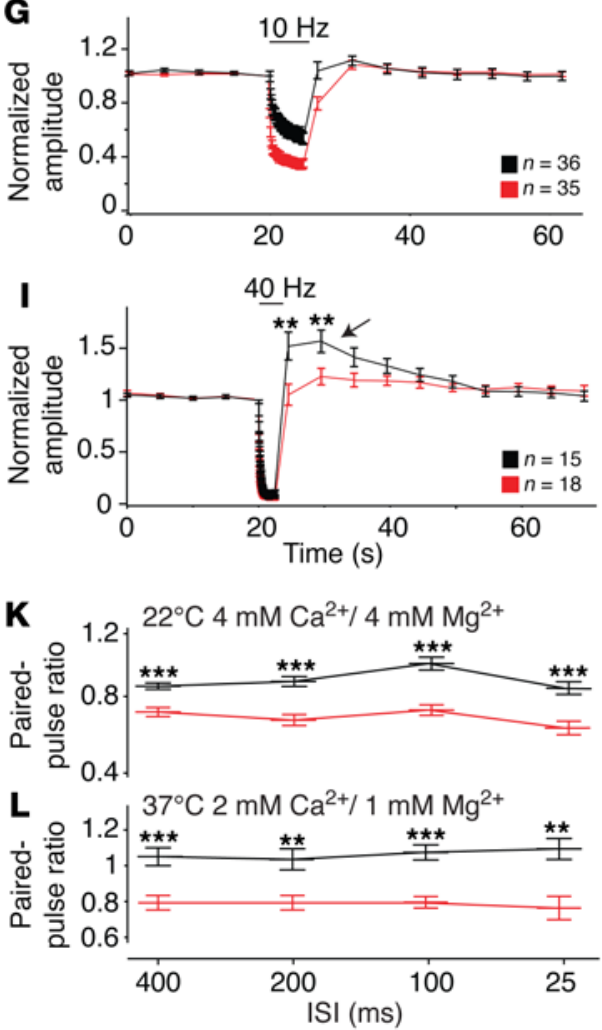

B $\quad 10 \mathrm{~Hz}$, inhibitory neurons Munc13-1 WT

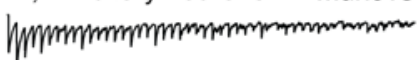

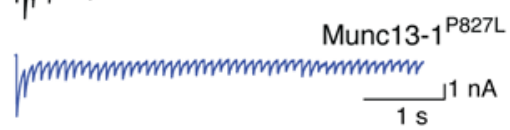

D

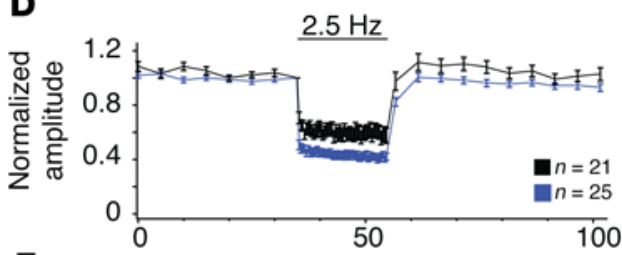

$\mathbf{F}$

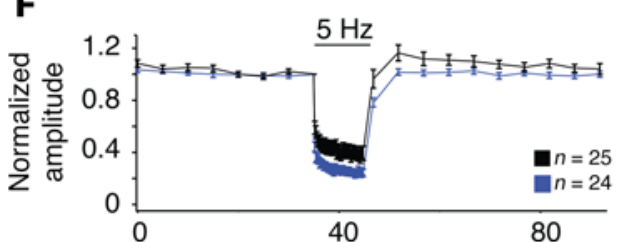

H

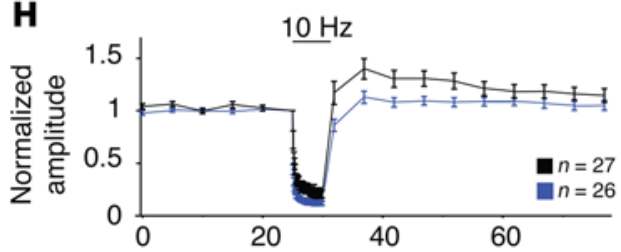

J
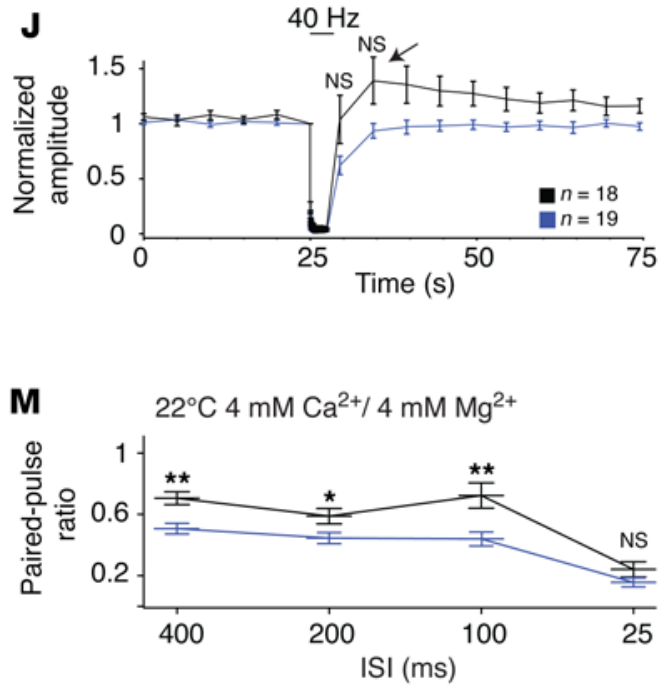

Figure 4. Munc13-1 ${ }^{\text {P827L }}$ alters synaptic STP. (A) Example traces from autaptic hippocampal Munc13-1 Munc13-2 DKO neurons expressing Munc13-1wT (black) or Munc13-1 ${ }^{\text {P227L }}$ (red) obtained during stimulation with an AP train at a frequency of $10 \mathrm{~Hz}$. (B) Example traces from autaptic striatal Munc13-1 Munc13-2 DKO neurons expressing Munc13-1 ${ }^{\text {WT }}$ (black) or Munc13-1 $1^{\text {P827 }}$ (blue) obtained during stimulation with an AP train at a frequency of $10 \mathrm{~Hz}$. (C-J) Munc13-1 Munc13-2 DKO hippocampal (left) or striatal (right) neurons expressing Munc13-1 ${ }^{\text {WT }}$ (black) or Munc13-1 $1^{\text {P827L }}$ (red/blue) were stimulated with $\mathrm{AP}$ trains at frequencies of $2.5 \mathrm{~Hz}$ (C and D), $5 \mathrm{~Hz}$ (E and $\mathbf{F}$ ), $10 \mathrm{~Hz}$ (G and $\mathbf{H}$ ), and $40 \mathrm{~Hz}$ (I and J), flanked by ongoing $0.2-\mathrm{Hz}$ stimulation. Amplitudes were normalized to the average amplitude before the train. In I and J, the point representing the recovery of the EPSC 7 seconds after the completion of the $40-\mathrm{Hz}$ train is labeled by an arrow. (K and $\mathbf{L}$ ) Average paired-pulse ratios (defined as the ratio of the amplitudes of the second to the first EPSC of the train), recorded with different interstimulus intervals (ISIs), in Munc13-1 Munc13-2 DKO hippocampal neurons expressing Munc13-1' ${ }^{\text {WT }}$ (black, $n=27-37$ ) or Munc13-1 $1^{\text {P227L (red, } n=29-36)}$ at $22^{\circ} \mathrm{C}, 4 \mathrm{mM} \mathrm{Ca}^{2+} / 4 \mathrm{mM} \mathrm{Mg}^{2+}(\mathbf{K})$, or at $37^{\circ} \mathrm{C}, 2 \mathrm{mM} \mathrm{Ca}^{2+} / 1 \mathrm{mM} \mathrm{Mg}^{2+}(\mathrm{L})$; Mann-Whitney test. (M) Average paired-pulse ratios, recorded with different ISIs, in Munc13-1 Munc13-2 DKO striatal neurons expressing Munc13-1WT (black, $n=19-27$ ) or Munc13-1 ${ }^{\text {P827L }}$ (blue, $n=18-24)$ at $22^{\circ} \mathrm{C}, 4 \mathrm{mM} \mathrm{Ca}^{2+} / 4 \mathrm{mM}$ $\mathrm{Mg}^{2+}$; Mann-Whitney test. All error bars in the figure represent mean \pm SEM . ${ }^{*} P<0.05$, ${ }^{*} P<0.01,{ }^{* * *} P<0.001$; NS, $P>0.05$. The data in $\mathbf{C}, \mathbf{E}, \mathbf{G}$, and $\mathbf{K}$ were obtained from 3 independent cultures. The data in $\mathbf{D}, \mathbf{F}, \mathbf{H}-\mathbf{J}, \mathbf{L}$, and $\mathbf{M}$ were obtained from 2 independent cultures. See Table 2 for further details. rather affects processes that act downstream of SV priming. In subsequent experiments, we tested whether the intrinsic fusion propensity, or fusogenicity, of SVs is changed by Munc13-1 $1^{\mathrm{P} 827 \mathrm{~L}}$, which would indicate a change in the composition or activity of the SV fusion machinery. To this end, we stimulated neurons expressing Munc13-1 ${ }^{\mathrm{WT}}$ or Munc13-1 ${ }^{\mathrm{P} 827 \mathrm{~L}}$ with $500 \mathrm{mM}$ sucrose, to determine the kinetics of RRP depletion, and with $250 \mathrm{mM}$ sucrose, which releases only a fraction of the RRP (32). An increase in SV fusogenicity under these experimental conditions manifests as an increase in the released RRP fraction and in the rate of RRP release in response to $250 \mathrm{mM}$ sucrose. We plotted the cumulative current integral of the sucrose-evoked PSC, normalized this to the RRP size determined by application of $500 \mathrm{mM}$ sucrose, and used a line fit to the maximum slope as an estimate for the peak fusion rate (measured in pools per second) (Figure 5, A-E, and Table 2). The peak rate of SV release during the application of $500 \mathrm{mM}$ sucrose was similar in neurons expressing Munc13- $1^{\mathrm{WT}}$ or Munc13-1 ${ }^{\mathrm{P} 827 \mathrm{~L}}$ $(P>0.05$; Figure 5C and Table 2$)$. However, the peak release rate measured upon application of $250 \mathrm{mM}$ sucrose was on average $50 \%$ accelerated in neurons expressing Munc13-1 ${ }^{\mathrm{P} 827 \mathrm{~L}}$ as compared with neurons expressing Munc13- $1^{\mathrm{WT}}(P<0.05$; Figure $5 \mathrm{C}$ and Table 2). Moreover, application of $250 \mathrm{mM}$ sucrose released on average a 2-fold larger fraction of the RRP in Munc13-1 ${ }^{\mathrm{P} 227 \mathrm{~L}}-$ expressing neurons ( $P<0.01$; Figure 5, D and E, and Table 2). 

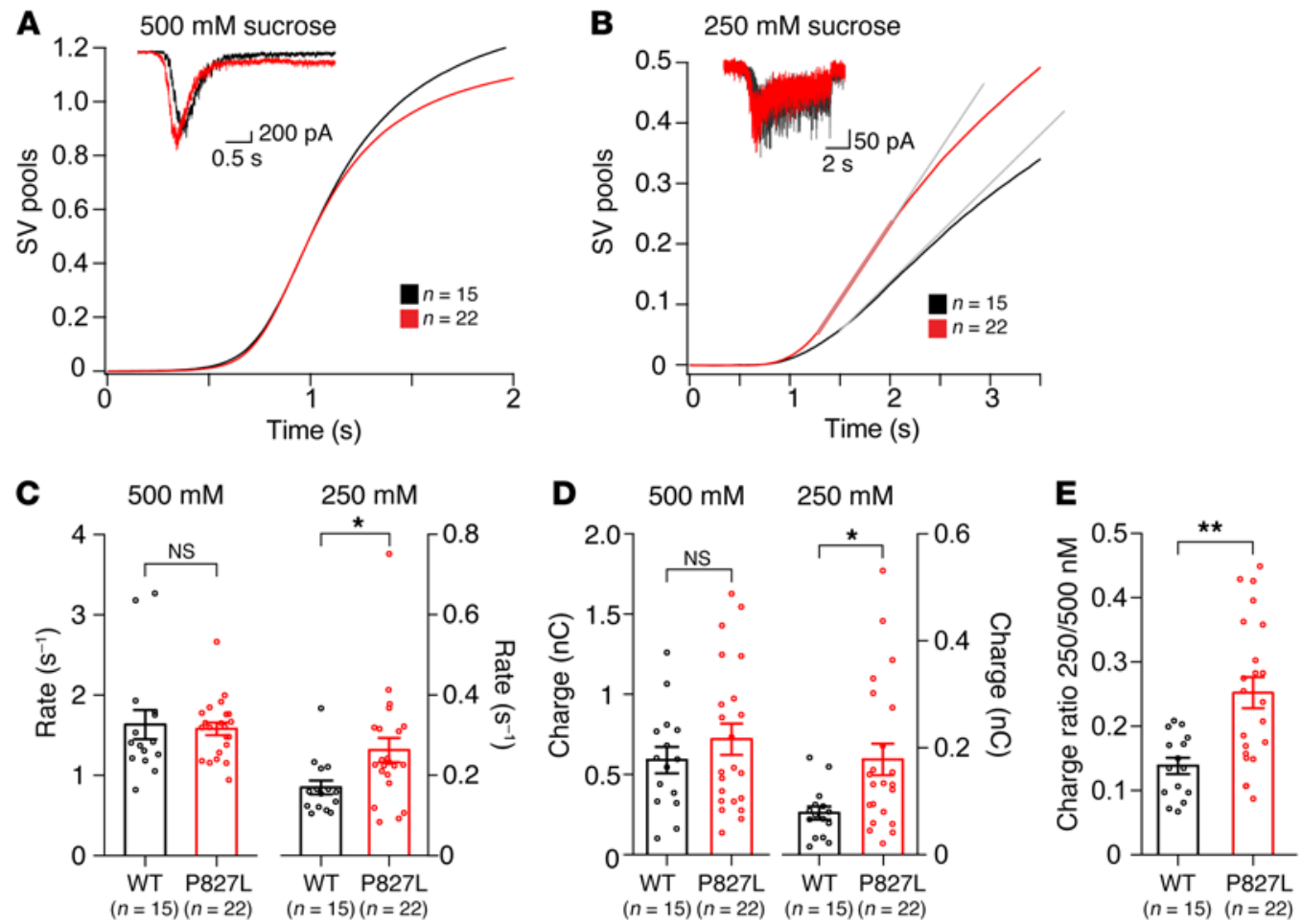

Figure 5. Munc13-1 ${ }^{\text {827L }}$ increases vesicular release probability by increasing SV fusogenicity. (A and B) Autaptic hippocampal neurons were stimulated with hypertonic sucrose solution. The traces were integrated, normalized to the RRP size, aligned, and averaged. The average integrals for Munc13-1 Munc13-2

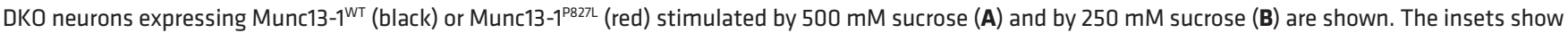

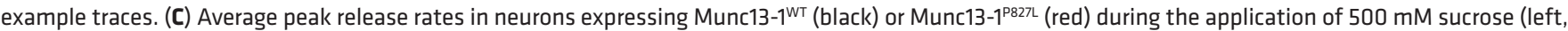
$P>0.05$ ) or $250 \mathrm{mM}$ sucrose (right, $P<0.05$ ). Individual values per neuron are indicated as circles (black, Munc13-1WT; red, Munc13-1 ${ }^{\text {P827L); }}$ Mann-Whitney test. (D) Average postsynaptic charge in neurons expressing Munc13-1WT (black) or Munc13-1 P827L (red) during the application of $500 \mathrm{mM}$ (left, $P>0.05$ ) or $250 \mathrm{mM}$ (right, $P<0.05$ ) sucrose; Mann-Whitney test. Individual values per neuron are indicated as circles (black, Munc13-1 ${ }^{\mathrm{WT}}$; red, Munc13-1 ${ }^{\mathrm{P} 827 \mathrm{~L}}$ ). (E) Average ratio of the postsynaptic charge triggered by the application of $250 \mathrm{mM}$ sucrose divided by that triggered by $500 \mathrm{mM}$ sucrose (see D). Individual values per neuron are indicated as circles (black, Munc13-1'WT; red, Munc13-1 ${ }^{p 227}$ ), $P<0.01$; Mann-Whitney test. All error bars in the figure represent mean $\pm S E M$. ${ }^{*} P<0.05$, ${ }^{*} P<0.01 ;$ NS, $P>0.05$. See Table 2 for further details.

Based on the data described in this section, we conclude that the Pro-Leu exchange in Munc13-1 causes a change in the activity or composition of the release machinery that leads to increased SV fusogenicity and a consequent increase of $\mathrm{p}_{\mathrm{r}}$.

\section{Discussion}

Munc13 proteins are essential for neurotransmitter release, and in mice, knockouts of Munc13-1 alone and of Munc13-1 and Munc13-2 in combination cause the most pervasive and specific presynaptic transmitter release defects identified to date $(25,26)$. We present here a patient with a dyskinetic movement disorder, delayed cognitive development, speech impairment, ASD, and ADHD, who carries a de novo heterozygous single-nucleotide exchange [NC_000019.9:g.17753685G>A (hg19), NM_0010804 21.2(UNC13A):c.2441C $>$ T, NM_001080421.2(UNC13A_i001):p. (Pro814Leu)] in the UNC13A gene on chromosome 19 (19p13.11) (Figure 1A). The mutation leads to the exchange of a highly conserved proline residue to leucine (Figure 1C), the novel allele is unique, and no other de novo variations were detected when WES data from the parents versus the patient were compared. Moreover, analysis of rare homozygous variations did not reveal other deleterious changes that could be associated with the clinical phenotype of the patient. The Pro-Leu exchange in mammalian
Munc13-1 leads to a gain of function that is characterized by an increased PSC amplitude, due to an increased initial $\mathrm{p}_{\mathrm{r}}$, in both excitatory and inhibitory neurons (Figure 3 ). We show further that the increased initial $\mathrm{p}_{\mathrm{r}}$ is caused, at least in part, by an increased SV fusogenicity (Figure 5). This functional synaptic change leads to substantial changes in the synaptic STP characteristics of the affected neurons (Figure 4). Finally, the corresponding Pro-Leu exchange in the UNC-13L protein in C. elegans causes a gain of function that is dominant over the WT isoform at the organism level (Figure 2, $\mathrm{F}$ and $\mathrm{G}$ ).

Based on the present data, we propose that the primary defect in synaptic transmission caused by the Pro-Leu mutation in UNC13A is a likely origin of the neurological and psychiatric dysfunction observed in the patient. This defined, functionally deleterious alteration in UNC13A/Munc13-1 adds the neuronal Munc13 proteins and the SV priming process that they control to the currently known etiological mechanisms of psychiatric and neurological synaptopathies. Beyond this, compensatory changes in response to the primary synaptic defect likely contribute to the clinical phenotype and its development over time. That this might indeed be the case is illustrated by the fact that aspects of the dyskinesia improved over time, but the cause of this improvement and its mechanism remain unclear. 
Mechanisms of Munc13-1 regulation. Munc13-1 contains multiple functional domains (Figure 1B). Loss-of-function mutations in the C2A domain or the MUN domain, or the genetic deletion of Munc13-1 expression, cause a strong or almost complete block of SV priming, RRP generation, and neurotransmitter release $(25,54$, $68,69)$. However, individual missense mutations in other functional domains of Munc13s lead to distinct synaptic defects, characterized by changes in RRP size, $\mathrm{p}_{\mathrm{r}}$, STP, or SV fusogenicity - or a combination thereof. For instance, point mutations that prevent $\mathrm{Ca}^{2+}$-calmodulin binding to Munc13-1 or $\mathrm{Ca}^{2+}$-dependent phospholipid binding to its C2B domain do not affect basal RRP formation but perturb RRP refilling during and after synaptic activity, with deleterious consequences for $\operatorname{STP}(33,34,37)$.

The phenotype caused by the Munc13-1 Pro-Leu exchange described here is most closely related to the effects of a gain-offunction mutation in the Munc13 C2B domain that increases the $\mathrm{Ca}^{2+}$-affinity of the C2B domain, leading to an increased $\mathrm{p}_{\mathrm{r}}$ with no change in the RRP size (37). In view of the similarity between the effects of this C2B mutation and the phenotype of the Munc13-1 variant described here, and given that the Pro-Leu exchange is, at the level of the primary sequence, close to the $\mathrm{C} 2 \mathrm{~B}$ domain (Figure $1 \mathrm{~B})$, it is possible that it affects the conformation or positioning of the $\mathrm{C} 2 \mathrm{~B}$ domain and hence modifies its $\mathrm{Ca}^{2+}$-affinity. It is of note in this regard that the present data reveal an increased rate of spontaneous SV fusion in the presence of Munc13-1 ${ }^{\mathrm{P} 827 \mathrm{~L}}$ already at resting $\mathrm{Ca}^{2+}$ concentrations, which is reflected by an increased mPSC frequency (Figure 3, E-H). How this phenomenon might be related to the function of the Munc13-1 C2B domain remains unknown, because the role of this domain has so far been studied mainly at high $\mathrm{Ca}^{2+}$ concentrations (37). An alternative explanation for the phenotype caused by the Munc13-1 ${ }^{\mathrm{P} 827 \mathrm{~L}}$ variant concerns a recently described presynaptic regulatory process, in the course of which Munc13 proteins modulate $\mathrm{Ca}^{2+}$ influx via voltage-gated $\mathrm{Ca}^{2+}$ channels (VGCCs) (70). The molecular mechanism of this process is not fully understood, but it involves the C2B domain of Munc13s, so it is possible that the Pro-Leu exchange in Munc13-1 affects VGCC function, leading to increased $\mathrm{Ca}^{2+}$ influx and increased $\mathrm{p}_{\mathrm{r}}$. Finally, it is possible that the Pro-Leu exchange affects the conformation of Munc13-1 or one of its protein-protein interactions, thereby leading to an "activation" of Munc13-1. Future experiments will have to determine which of these scenarios applies.

Munc13-related brain disorders. Studies using bioinformatic analysis of WES and of single-nucleotide polymorphism databases have shed light on the large polygenic contribution of rare and disruptive mutations to the etiology of psychiatric, neurodevelopmental, and neurodegenerative diseases $(20,23,24)$. Interestingly, the corresponding genetic variants are distributed across a large number of genes that can be mapped to a limited number of biological pathways $(20,22,23)$, and several of the risk alleles are found to contribute to multiple diseases (20). Among many others, variants of neuronal Munc13s have been detected as risk factors in ASD (23) and schizophrenia (22, 24, 71). However, the links between the respective genetic variations and their functional consequences at the protein, synapse, or cellular levels are at the moment tentative at best. For instance, a rare, de novo, heterozygous variation in the MUN domain of UNC13A (Met1269Ile) was identified in a schizophrenia patient (ref. 22 and Figure 1B). Amino acid alignment shows that Met1269 is conserved in Munc13 isoforms from several species, but replaced by an isoleucine in the zebrafish ortholog (Danio rerio) (Supplemental Figure 3A). We analyzed this Met-Ile exchange by the same approach described above for the Pro814Leu exchange, but found no phenotypic changes with respect to the functional parameters characterizing synaptic transmission in autapses (Supplemental Figure 3). It is therefore difficult to assign an etiological role to this genetic variation in the context of schizophrenia, although it may act in combination with other genetic, epigenetic, or environmental perturbations to produce an effect on synaptic transmission and, ultimately, on schizophrenia-related behavioral outputs. Hence, our present analysis of disease-linked UNC13A variants illustrates the power of combining WES in patients with functional analyses of the corresponding genetic variations in reliable and standardized model systems to determine etiological processes in psychiatric and neurological disorders.

Very recently, a homozygous nonsense mutation leading to the truncation of UNC13A after amino acid residue 101 was found in a patient suffering from a fatal syndrome with microcephaly, cortical hyperexcitability, and myasthenia (46). The corresponding mutation eliminates all functionally relevant Munc13-1 domains, except for the RIM-binding C2A domain, which is C-terminally truncated by approximately 25 residues, suggesting a major loss of function. Some aspects of the patient's symptoms, such as a strong reduction in neuromuscular synaptic transmission, resemble the phenotype of Munc13-1-deficient mice (45). On the other hand, the patient's microcephaly is not phenocopied in mouse models, where even the combined deletion of all relevant Munc13 variants leaves brain development intact (26), indicating that the patient may express a truncated N-terminal Munc13-1 fragment with a dominant-negative function. In any case, the clinical phenotype of this truncation mutation is strikingly different from the one described in the present study, and the functional consequences of the remaining Munc13-1 fragment have so far not been tested.

A key conclusion of the present study is that even a single point mutation in Munc13-1 can lead to profoundly aberrant function of the protein, with deleterious consequences for synaptic transmission and for STP in culture. Such changes, and the accompanying compensatory changes in the neuron, are highly likely to affect neuronal network activity and thus may lead to very complex psychiatric and neurological deficits, as seen here in the patient. The complexity of functional phenotypes caused by loss of Munc13-1 and by different Munc13-1 mutants studied so far in cultured neurons and in mouse models, along with the widespread expression of Munc13-1 in the CNS, explains the involvement of Munc13-1 in multiple clinical phenotypes. In turn, this functional complexity currently limits a phenotype-based, systematic search for patients with altered Munc13-1 primary structure. Given the key functional role of Munc13s in the CNS, we anticipate that the increased use of WES as a diagnostic tool will lead to the discovery of further Munc13-related disorders.

Munc13s and the synaptic basis of dyskinesia. The patient described in the present study suffers from dyskinesia characterized by hyperkinesia with continuous movements, sudden recurrence of abnormal movements, choreoathetosis, and tremor (Supplemental Video 1). Dyskinesias are thought to involve basal 
ganglia and possibly cerebellar dysfunction (72), and have a strong genetic component. Indeed, several gene variations have been linked to familial forms of dyskinesia. Paroxysmal nonkinesigenic dyskinesia (PNKD), for instance, is caused by variations in PNKD, a protein that likely acts as a hydroxyacylglutathione hydrolase and detoxifies methylglyoxal (16). PNKD is a synaptic protein that interacts with the C-terminal $\mathrm{C} 2 \mathrm{~B}$ domain of the presynaptic active zone proteins RIM1 and RIM2. This RIM interaction is weakened by disease-causing mutations in PNKD, and PNKD KO mice show reduced levels of RIM1 and RIM2 (18). PNKD overexpression inhibits synaptic transmission, and PNKD KO mice show reduced dopaminergic and glutamatergic synaptic transmission $(18,73)$. Like PNKD, Munc13s are RIM interactors. They bind to the N-terminal zinc finger domain of RIMs, and the DKO of RIM1 and RIM2 in mice causes an approximately 50\% reduction of Munc13-1 levels, likely due to mistargeting of Munc13-1 and premature degradation (74). In view of these functional relationships, it is possible that PNKD affects synaptic transmission not only by modulating RIMs themselves (18) but also by indirectly affecting the presynaptic localization or function of Munc13s (75).

A second protein of relevance in the context of Munc13-1 function and dyskinesia is PRRT2, a synaptic proline-rich transmembrane protein that binds the SNARE protein $\operatorname{SNAP} 25(17,76)$ and synaptotagmin 1 and synaptotagmin 2 (77). PRRT2 variants are linked to paroxysmal kinesigenic dyskinesia with infantile epilepsy (PKD/IC) (17) and fever-related infantile seizures (78). Reduced PRRT2 levels cause a complex phenotype, including a reduction in synapse numbers, a parallel increase in SV numbers and in the RRP size at the remaining synapses, reductions in the frequency and amplitude of spontaneous synaptic events, and reduced APevoked EPSCs (77). These findings indicate that PRRT2 is involved in the control of $\mathrm{p}_{\mathrm{r}}$, and it was suggested that it functionally links the SNARE complex and synaptotagmins to increase the $\mathrm{Ca}^{2+}$ sensitivity of the SV fusion machinery.

In summary, several lines of genetic evidence, including the present study, indicate that mutations in presynaptic proteins play a key role in dyskinesias. Future experiments will determine whether the corresponding proteins truly interact functionally, so that their perturbation leads to similar clinical phenotypes.

Model validity and outlook. As the primary sequences of human and murine Munc13-1 are essentially identical ( $95 \%$ identity), one can safely assume that neurons expressing murine Munc13-1 ${ }^{\mathrm{P} 827 \mathrm{~L}}$ have construct validity as models for human Munc13-1 ${ }^{\mathrm{P} 814 \mathrm{~L}}$ neurons (Figure 1C). However, whether the phenotypic changes we observed in Munc13-1 $1^{\mathrm{P} 227 \mathrm{~L}}$ mouse neurons can be extended to human neurons is difficult to assess unequivocally at this point because electrophysiological measurements in human patients at the level done in the present study are out of reach. One way forward would be to perform electrophysiological recordings in neurons derived from induced pluripotent stem cells of the patient.

Generally, synapses are amenable to therapeutic intervention, as is exemplified by many synapse-directed pharmacological treatment regimes in psychiatry and neurology (1-4). Munc13s have several regulatory domains that modulate their function at synapses, including a $\mathrm{Ca}^{2+}$-calmodulin binding domain, a diacylglycerol- and phorbol ester-binding C1 domain, and a C2 domain (C2B) that binds to $\mathrm{Ca}^{2+}$ and phospholipids (Figure 1B). By target- ing these domains, it would in principle be possible to regulate Munc13s pharmacologically in order to affect SV fusogenicity and $\mathrm{p}_{\mathrm{r}}$. Beyond this, a general and not necessarily Munc13-1-specific negative pharmacological interference with presynaptic $\mathrm{p}_{\mathrm{r}}$ might be of therapeutic value for the patient described here.

\section{Methods}

Patient phenotyping. Clinical phenotyping was carried out by a multidisciplinary team consisting of pediatricians specialized in metabolic disorders, clinical geneticists, neurologists, child and adolescent psychiatrists, a physical therapist, and neuropsychologists. Psychiatric evaluation was performed using a systematic screening according to the DSM-IV criteria (79). Additionally, the Autism Diagnostic Observation Schedule 2 (ADOS-2) module 2 (80) and the Autism Diagnostic Interview Revised (ADI-R) (81) were performed to examine the possibility of ASD. For the assessment of developmental and cognitive levels, we used the BSID $(47,48)$ and Wechsler $(49)$, respectively.

WES and bioinformatics. Genomic DNA was isolated from wholeblood samples of the patient and his parents using standard manual or robotic procedures, and trio-WES was performed as reported (82), with the exception that the Agilent SureSelect Human All Exon 50Mb Kit V4 was used for enrichment, and sequencing was performed according to the manufacturer's protocol on the Solid5500 sequencing platform (Life Technologies). Alignment and variant annotation was performed as reported (82). Filter settings were optimized for discovery of de novo heterozygous variants. Minimum coverage was 10 reads, and the setting for variant allele percentage was $15 \%$. All variants present in Ensembl62 and in our in-house database were filtered out. The remaining variants present only in the patient and not in his parents were considered as novel. Analyses of rare homozygous variants present at a population frequency of less than $0.5 \%$ were performed using the large-scale variant population frequency databases of the Exome Aggregation Consortium (ExAC) (50) and the Genome of the Netherlands (GoNL) (51) (all accessed September 2016) (Table 1). We evaluated whether the identified variants lead to loss/change of function due to proximity to a splice site, generation of a premature stop codon, introduction of a frameshift, or predicted effect on protein function by PolyPhen-2 (52) and SIFT (53). The resulting variants were classified according to their function and possible link to the patient's phenotype. Filtering and Sanger confirmations for a de novo model yielded a single missense variation in UNC13A, predicted to be possibly damaging (PolyPhen-2) and deleterious (SIFT).

DNA construct and virus preparation. Munc13-1-EGFP in the lentiviral vector $\mathrm{p}$ (syn)Wrbn was mutated to contain the Pro827Leu mutation or the Met1269lle mutation. Lentiviral particles were prepared as reported $(83,84)$, and autaptic neurons were infected at DIV2-3.

Culture preparation and electrophysiological recordings. Microisland cultures of mouse hippocampal or striatal neurons were prepared as previously described $(55,85,86)$. Cultures were kept at $37^{\circ} \mathrm{C}$ and $5 \% \mathrm{CO}_{2}$ until recordings were made at DIV14-16. Whole-cell voltage-clamp data were acquired using the Axon Multiclamp 700B amplifier, Digidata 1440A data acquisition system, and pCLAMP 10 software (Molecular Devices). All recordings were performed using a standard external solution containing $140 \mathrm{mM} \mathrm{NaCl}, 2.4 \mathrm{mM} \mathrm{KCl}$, $10 \mathrm{mM}$ HEPES, $10 \mathrm{mM}$ glucose, $4 \mathrm{mM} \mathrm{CaCl}_{2}$, and $4 \mathrm{mM} \mathrm{MgCl}_{2}$ (320 $\mathrm{mOsm} / \mathrm{l})$, unless otherwise indicated. The standard internal solution contained $136 \mathrm{mM} \mathrm{KCl}, 17.8 \mathrm{mM}$ HEPES, 1 mM EGTA, $4.6 \mathrm{mM}$ 
$\mathrm{MgCl}_{2}, 4 \mathrm{mM}$ NaATP, $0.3 \mathrm{mM} \mathrm{Na} \mathrm{GTP}_{2}, 15 \mathrm{mM}$ creatine phosphate, and $5 \mathrm{U} / \mathrm{ml}$ phosphocreatine kinase (315-320 mOsm/l), pH 7.4. EPSCs or IPSCs were evoked by depolarization of the cell from -70 to $0 \mathrm{mV}$ for $2 \mathrm{~ms}$. The external solution was changed during the various protocols using a custom-made fast-flow system controlled by a stepper motor that allows complete and rapid solution exchange around the neuron. Recordings were made at room temperature $\left(22^{\circ} \mathrm{C}\right)$ or, when indicated, at physiological temperature $\left(35^{\circ} \mathrm{C}-37^{\circ} \mathrm{C}\right)$. Heating of the external solution was achieved via an automatic temperature controller (TC-321B, Warner Instruments). Release of the RRP was measured in response to application of $500 \mathrm{mM}$ (7 seconds) or $250 \mathrm{mM}$ (10 seconds) sucrose in the external solution. To determine the average peak release rates during the sucrose application, the traces were integrated, normalized to the RRP size, aligned, and averaged. The peak release rate corresponds to the maximum slope of the normalized integrated PSC. mEPSCs and mIPSCs were recorded for 100 seconds in the presence of $300 \mathrm{nM}$ tetrodotoxin. PDBU $(1 \mu \mathrm{M})$ was applied for 2 minutes. Analyses were performed using Axograph 1.4.3 (Molecular Devices) or Igor Pro (Wavemetrics).

C. elegans strains and behavioral assays. Strains were maintained and genetically manipulated as previously described (60). In brief, animals were raised at $20^{\circ} \mathrm{C}$ on nematode growth media seeded with OP50. Strains used were N2 and unc-13(s69). Transgenic strains used were JSD832, tauEx310[Psnb1::unc-13(P956L) ins69];JSD951, tauEx377[Psnb1::UNC-13 (P956L) in N2]; JSD968, tauEx384[Psnb1::UNC-13 (FL) in s69]; and JSD969, tauEx385[Psnb1::UNC-13 (FL) in N2]. All UNC-13 expression constructs used encoded the long-form isoform of UNC-13 (UNC-13L). To measure aldicarb sensitivity, 20-25 young adult animals were placed on agar plates containing $1 \mathrm{mM}$ aldicarb (Watson International). Paralysis was scored with 10-minute intervals over 2 hours. Each genotype was tested at least 10 times, and paralysis curves were generated by averaging of paralysis time courses for each plate as described previously (87).

Statistics. Electrophysiological data are presented as mean \pm SEM. Statistical significance was determined using the Mann-Whitney test. For the C. elegans paralysis assay, data were analyzed using ANOVA statistics and Tukey-Kramer as a post hoc test for significance of all pairwise comparisons. In Supplemental Figure 2, the KolmogorovSmirnov nonparametric test for probability distributions was used.

Study approval. The patient's parents provided written, informed consent for all aspects of the study according to Dutch law, including publication of identifiable material. The generation, maintenance, and use of Munc13 mutant mice were approved by the responsible local government organization (Niedersächsisches Landesamt für Verbraucherschutz und Lebensmittelsicherheit; 33.9.42502-04-13/1359 and 33.19-42502-04-15/1817).

\section{Author contributions}

NL, JJJ, NC, TAR, HT, JSR, OJ, and NB designed the study. Clinical phenotyping, patient care, and (genetic) counseling were provided by GV, RvE, MMvH, IC, HCvT, AMVE, PMvH, and JAV. NMVD, GvH, and GRM performed WES and bioinformatics. KJD performed Sanger sequencing confirmation and DNA construct preparation. NL cloned and prepared the viral particles, and performed and analyzed the electrophysiological experiments. KP participated in the cloning and preparation of viruses. JSR and HT supervised the electrophysiological recordings and analysis. HT wrote the algorithms used for part of the analysis. FEM created the C. elegans strains and performed the experiments as initiated and planned by JSD. NL, NB, GV, GRM, ST, and JJJ wrote the paper.

\section{Acknowledgments}

We are extremely grateful for the contribution of the patient's family to this study. We thank Christian Rosenmund (Berlin, Germany) for the gift of a viral expression vector; Fritz Benseler, the AGCT laboratory, Anja Günther, and Astrid Zeuch (Göttingen, Germany) for excellent technical support; Edwin Cuppen for facilitating WES; Marjolein van Susante and Karlijn Daniels-Steggehuis for psychological assessments; and the staff of the Max Planck Institute of Experimental Medicine Animal Facility (Göttingen, Germany) for mouse husbandry. This work was supported by the Max Planck Society (Munich, Germany; to NB), the European Research Council (Brussels, Belgium; ERC-ADG SYNPRIME to NB), the German Research Foundation (Bonn, Germany; CNMPB FZT103 to NB), and the NIH (NIH/NIGMS R01GM095674 to JSD, T32GM007739 to FEM).

Address correspondence to: Judith J. Jans, Department of Genetics, Utrecht University Medical Center, Lundlaan 6, 3584 CX Utrecht, the Netherlands. Phone: 31-88-7554612; E-mail: J.J.M.Jans@ umcutrecht.nl. Or to: Nils Brose, Department of Molecular Neurobiology, Max Planck Institute of Experimental Medicine, Hermann-Rein-Straße 3, 37075 Göttingen, Germany. Phone: 49551-3899725; E-mail: brose@em.mpg.de.
1. Blier P, El Mansari M. Serotonin and beyond: therapeutics for major depression. Philos Trans $R$ Soc Lond B Biol Sci. 2013;368(1615):20120536.

2. Boyd KN, Mailman RB. Dopamine receptor signaling and current and future antipsychotic drugs. Handb Exp Pharmacol. 2012;(212):53-86.

3. Musazzi L, Treccani G, Mallei A, Popoli M. The action of antidepressants on the glutamate system: regulation of glutamate release and glutamate receptors. Biol Psychiatry. 2013;73(12):1180-1188.

4. Agid Y, et al. How can drug discovery for psychiatric disorders be improved? Nat Rev Drug Discov. 2007;6(3):189-201.

5. Südhof TC. Neurotransmitter release: the last millisecond in the life of a synaptic vesicle. Neu- ron. 2013;80(3):675-690.

6. Wojcik SM, Brose N. Regulation of membrane fusion in synaptic excitation-secretion coupling: speed and accuracy matter. Neuron. 2007;55(1):11-24.

7. Giovedí S, Corradi A, Fassio A, Benfenati F. Involvement of synaptic genes in the pathogenesis of autism spectrum disorders: the case of synapsins. Front Pediatr. 2014;2:94.

8. Hamdan FF, et al. De novo STXBP1 mutations in mental retardation and nonsyndromic epilepsy. Ann Neurol. 2009;65(6):748-753.

9. Deprez L, et al. Clinical spectrum of earlyonset epileptic encephalopathies associated with STXBP1 mutations. Neurology. 2010;75(13):1159-1165.
10. Carvill GL, et al. GABRA1 and STXBP1: novel genetic causes of Dravet syndrome. Neurology. 2014;82(14):1245-1253.

11. Otsuka M, et al. STXBP1 mutations cause not only Ohtahara syndrome but also West syndrome - result of Japanese cohort study. Epilepsia. 2010;51(12):2449-2452.

12. Saitsu $\mathrm{H}$, et al. De novo mutations in the gene encoding STXBP1 (MUNC18-1) cause early infantile epileptic encephalopathy. Nat Genet. 2008;40(6):782-788.

13. Nosková L, et al. Mutations in DNAJC5, encoding cysteine-string protein $\alpha$, cause autosomal-dominant adult-onset neuronal ceroid lipofuscinosis. Am J Hum Genet. 2011;89(2):241-252.

14. Ozansoy M, Başak AN. The central theme of 
Parkinson's disease: $\alpha$-synuclein. Mol Neurobiol. 2013;47(2):460-465.

15. Rizo J, Südhof TC. The membrane fusion enigma: SNAREs, Sec1/Munc18 proteins, and their accomplices - guilty as charged? Annu Rev Cell Dev Biol. 2012;28:279-308.

16. Lee HY, et al. The gene for paroxysmal nonkinesigenic dyskinesia encodes an enzyme in a stress response pathway. Hum Mol Genet. 2004;13(24):3161-3170.

17. Lee HY, et al. Mutations in the gene PRRT2 cause paroxysmal kinesigenic dyskinesia with infantile convulsions. Cell Rep. 2012;1(1):2-12.

18. Shen $Y$, et al. Protein mutated in paroxysmal dyskinesia interacts with the active zone protein RIM and suppresses synaptic vesicle exocytosis. Proc Natl Acad Sci U S A. 2015;112(10):2935-2941.

19. Baker K, et al. Identification of a human synaptotagmin-1 mutation that perturbs synaptic vesicle cycling. J Clin Invest. 2015;125(4):1670-1678.

20. Cross-Disorder Group of the Psychiatric Genomics Consortium. Identification of risk loci with shared effects on five major psychiatric disorders: a genome-wide analysis. Lancet. 2013;381(9875):1371-1379.

21. De Rubeis S, et al. Synaptic, transcriptional and chromatin genes disrupted in autism. Nature. 2014;515(7526):209-215.

22. Fromer M, et al. De novo mutations in schizophrenia implicate synaptic networks. Nature. 2014;506(7487):179-184.

23. Gai X, et al. Rare structural variation of synapse and neurotransmission genes in autism. Mol Psychiatry. 2012;17(4):402-411.

24. Purcell SM, et al. A polygenic burden of rare disruptive mutations in schizophrenia. Nature. 2014;506(7487):185-190.

25. Augustin I, Rosenmund C, Südhof TC, Brose N. Munc13-1 is essential for fusion competence of glutamatergic synaptic vesicles. Nature. 1999;400(6743):457-461.

26. Varoqueaux F, et al. Total arrest of spontaneous and evoked synaptic transmission but normal synaptogenesis in the absence of Munc13-mediated vesicle priming. Proc Natl Acad Sci U S A. 2002;99(13):9037-9042.

27. Ashery U, et al. Munc13-1 acts as a priming factor for large dense-core vesicles in bovine chromaffin cells. EMBO J. 2000;19(14):3586-3596.

28. Augustin I, et al. The cerebellum-specific Munc13 isoform Munc13-3 regulates cerebellar synaptic transmission and motor learning in mice. J Neurosci. 2001;21(1):10-17.

29. Rosenmund C, Sigler A, Augustin I, Reim K, Brose N, Rhee JS. Differential control of vesicle priming and short-term plasticity by Munc13 isoforms. Neuron. 2002;33(3):411-424.

30. Richmond JE, Weimer RM, Jorgensen EM. An open form of syntaxin bypasses the requirement for UNC-13 in vesicle priming. Nature. 2001;412(6844):338-341.

31. Yang $X$, et al. Syntaxin opening by the MUN domain underlies the function of Munc13 in synaptic-vesicle priming. Nat Struct Mol Biol. 2015;22(7):547-554.

32. Basu J, Betz A, Brose N, Rosenmund C. Munc13-1 $\mathrm{C} 1$ domain activation lowers the energy barrier for synaptic vesicle fusion. J Neurosci.
2007;27(5):1200-1210.

33. Junge $\mathrm{HJ}$, et al. Calmodulin and Munc13 form a $\mathrm{Ca}^{2+}$ sensor/effector complex that controls short-term synaptic plasticity. Cell. 2004;118(3):389-401.

34. Lipstein N, et al. Dynamic control of synaptic vesicle replenishment and short-term plasticity by $\mathrm{Ca}(2+)$-calmodulin-Munc13-1 signaling. $\mathrm{Neu}$ ron. 2013;79(1):82-96.

35. Lipstein $\mathrm{N}$, et al. Nonconserved $\mathrm{Ca}(2+) / \mathrm{calmodu}-$ lin binding sites in Munc13s differentially control synaptic short-term plasticity. Mol Cell Biol. 2012;32(22):4628-4641.

36. Rhee JS, et al. Beta phorbol ester- and diacylglycerol-induced augmentation of transmitter release is mediated by Munc13s and not by PKCs. Cell. 2002;108(1):121-133.

37. Shin $\mathrm{OH}$, et al. Munc13 C2B domain is an activitydependent $\mathrm{Ca}^{2+}$ regulator of synaptic exocytosis. Nat Struct Mol Biol. 2010;17(3):280-288.

38. Abbott LF, Varela JA, Sen K, Nelson SB. Synaptic depression and cortical gain control. Science. 1997;275(5297):220-224

39. Chung S, Li X, Nelson SB. Short-term depression at thalamocortical synapses contributes to rapid adaptation of cortical sensory responses in vivo. Neuron. 2002;34(3):437-446.

40. Nadim F, Manor Y. The role of short-term synaptic dynamics in motor control. Curr Opin Neurobiol. 2000;10(6):683-690.

41. Nadim F, Manor Y, Kopell N, Marder E. Synaptic depression creates a switch that controls the frequency of an oscillatory circuit. Proc Natl Acad Sci U S A. 1999;96(14):8206-8211.

42. Mongillo G, Barak O, Tsodyks M. Synaptic theory of working memory. Science. 2008;319(5869):1543-1546.

43. Traub RD, et al. Transient depression of excitatory synapses on interneurons contributes to epileptiform bursts during gamma oscillations in the mouse hippocampal slice. J Neurophysiol. 2005;94(2):1225-1235.

44. Augustin I, Betz A, Herrmann C, Jo T, Brose N. Differential expression of two novel Munc13 proteins in rat brain. Biochem J. 1999;337(pt 3):363-371.

45. Varoqueaux F, Sons MS, Plomp JJ, Brose N. Aberrant morphology and residual transmitter release at the Munc13-deficient mouse neuromuscular synapse. Mol Cell Biol. 2005;25(14):5973-5984.

46. Engel AG, Selcen D, Shen XM, Milone M, Harper CM. Loss of MUNC13-1 function causes microcephaly, cortical hyperexcitability, and fatal myasthenia. Neurol Genet. 2016;2(5):e105.

47. Bayley N. Manual for the Bayley Scales of Infant Development. 2nd ed. San Antonio, Texas, USA: The Psychological Corp.; 1993.

48. Meulen BFvd, Ruiter SAJ, Lutje Spelberg HC, Smrkovský M. Bayley Scales of Infant Development-II-Dutch Adaptation. Amsterdam, Netherlands: Harcourt Test Publishers; 2004.

49. Werpup-Stüwe L, Petermann F, Daseking M. [The impact of visual perceptual abilities on the performance on the Wechsler nonverbal scale of ability (WNV)]. Gesundheitswesen. 2015;77(10):799-804.

50. Lek M, et al. Analysis of protein-coding genetic variation in 60,706 humans. Nature. 2016;536(7616):285-291.

51. Genome of the Netherlands Consortium. Whole- genome sequence variation, population structure and demographic history of the Dutch population. Nat Genet. 2014;46(8):818-825.

52. Adzhubei IA, et al. A method and server for predicting damaging missense mutations. Nat Methods. 2010;7(4):248-249.

53. Ng PC, Henikoff S. SIFT: Predicting amino acid changes that affect protein function. Nucleic Acids Res. 2003;31(13):3812-3814.

54. Basu J, et al. A minimal domain responsible for Munc13 activity. Nat Struct Mol Biol. 2005;12(11):1017-1018.

55. Burgalossi A, et al. Analysis of neurotransmitter release mechanisms by photolysis of caged $\mathrm{Ca}^{2+}$ in an autaptic neuron culture system. Nat Protoc. 2012;7(7):1351-1365.

56. Jockusch WJ, et al. CAPS- 1 and CAPS- 2 are essential synaptic vesicle priming proteins. Cell. 2007;131(4):796-808.

57. Rhee JS, et al. Augmenting neurotransmitter release by enhancing the apparent $\mathrm{Ca}^{2+}$ affinity of synaptotagmin 1. Proc Natl Acad Sci U S A. 2005;102(51):18664-18669.

58. Xue M, et al. Distinct domains of complexin I differentially regulate neurotransmitter release. $\mathrm{Nat}$ Struct Mol Biol. 2007;14(10):949-958.

59. Imig C, et al. The morphological and molecular nature of synaptic vesicle priming at presynaptic active zones. Neuron. 2014;84(2):416-431.

60. Brenner $S$. The genetics of Caenorhabditis elegans. Genetics. 1974;77(1):71-94.

61. Mahoney TR, Luo S, Nonet ML. Analysis of synaptic transmission in Caenorhabditis elegans using an aldicarb-sensitivity assay. Nat Protoc. 2006;1(4):1772-1777.

62. Rosenmund C, Stevens CF. Definition of the readily releasable pool of vesicles at hippocampal synapses. Neuron. 1996;16(6):1197-1207.

63. Betz A, et al. Munc13-1 is a presynaptic phorbol ester receptor that enhances neurotransmitter release. Neuron. 1998;21(1):123-136.

64. Wierda KD, Toonen RF, de Wit H, Brussaard AB, Verhage $\mathrm{M}$. Interdependence of PKC-dependen and PKC-independent pathways for presynaptic plasticity. Neuron. 2007;54(2):275-290.

65. Lou X, Korogod N, Brose N, Schneggenburger R. Phorbol esters modulate spontaneous and $\mathrm{Ca}^{2+}$-evoked transmitter release via acting on both Munc13 and protein kinase C. JNeurosci. 2008;28(33):8257-8267.

66. de Jong AP, et al. Phosphorylation of synaptotagmin-1 controls a post-priming step in PKCdependent presynaptic plasticity. Proc Natl Acad Sci U S A. 2016;113(18):5095-5100.

67. Wesseling JF, Lo DC. Limit on the role of activity in controlling the release-ready supply of synaptic vesicles. J Neurosci. 2002;22(22):9708-9720.

68. Betz A, et al. Functional interaction of the active zone proteins Munc13-1 and RIM1 in synaptic vesicle priming. Neuron. 2001;30(1):183-196.

69. Stevens DR, et al. Identification of the minimal protein domain required for priming activity of Munc13-1. Curr Biol. 2005;15(24):2243-2248.

70. Calloway N, Gouzer G, Xue M, Ryan TA. The active-zone protein Munc13 controls the usedependence of presynaptic voltage-gated calcium channels. Elife. 2015;4:e07728.

71. Egawa J, et al. Rare UNC13B variations and risk 
of schizophrenia: Whole-exome sequencing in a multiplex family and follow-up resequencing and a case-control study. Am JMed Genet B Neuropsychiatr Genet. 2016;171(6):797-805.

72. Pizoli CE, Jinnah HA, Billingsley ML, Hess EJ. Abnormal cerebellar signaling induces dystonia in mice. J Neurosci. 2002;22(17):7825-7833.

73. Lee HY, et al. Dopamine dysregulation in a mouse model of paroxysmal nonkinesigenic dyskinesia. J Clin Invest. 2012;122(2):507-518.

74. Schoch S, et al. RIM1alpha forms a protein scaffold for regulating neurotransmitter release at the active zone. Nature. 2002;415(6869):321-326.

75. Lu J, et al. Structural basis for a Munc13-1 homodimer to Munc13-1/RIM heterodimer switch. PLoS Biol. 2006;4(7):e192.

76. Stelzl U, et al. A human protein-protein interaction network: a resource for annotating the proteome. Cell. 2005;122(6):957-968.

77. Valente P, et al. PRRT2 is a key component of the $\mathrm{Ca}(2+)$-dependent neurotransmitter release machinery. Cell Rep. 2016;15(1):117-131.

78. Scheffer IE, et al. PRRT2 phenotypic spectrum includes sporadic and fever-related infantile sei- zures. Neurology. 2012;79(21):2104-2108.

79. American Psychiatric Association. Diagnostic and Statistical Manual of Mental Disorders. 4th ed., text revision. Washington, DC, USA: American Psychiatric Press; 2000.

80. Annelies de Bildt MdJ, Greaves-Lord K. ADOS-2 Autisme Diagnostisch Observatieschema Hogrefe; 2013.

81. Maretha de Jonge AdB, Ann Le Couteur, Catherine Lord, Michael Rutter. ADI-R Autisme Diagnostisch Interview-Revised. Hogrefe; 2012.

82. Harakalova M, et al. Dominant missense mutations in ABCC9 cause Cantú syndrome. Nat Genet. 2012;44(7):793-796.

83. Hsia HE, et al. Ubiquitin E3 ligase Nedd4-1 acts as a downstream target of PI3K/PTEN-mTORC1 signaling to promote neurite growth. Proc Natl Acad Sci U S A. 2014;111(36):13205-13210.

84. Naldini L, et al. In vivo gene delivery and stable transduction of nondividing cells by a lentiviral vector. Science. 1996;272(5259):263-267.

85. Bekkers JM, Stevens CF. Excitatory and inhibitory autaptic currents in isolated hippocampal neurons maintained in cell culture. Proc Natl
Acad Sci U S A. 1991;88(17):7834-7838.

86. Nair R, et al. Neurobeachin regulates neurotransmitter receptor trafficking to synapses. J Cell Biol. 2013;200(1):61-80.

87. Dittman JS, Kaplan JM. Behavioral impact of neurotransmitter-activated G-protein-coupled receptors: muscarinic and $\mathrm{GABAB}$ receptors regulate Caenorhabditis elegans locomotion. JNeurosci. 2008;28(28):7104-7112.

88. Koch H, Hofmann K, Brose N. Definition of Munc13-homology-domains and characterization of a novel ubiquitously expressed Munc13 isoform. Biochem J. 2000;349(pt 1):247-253.

89. Liu X, et al. Functional synergy between the Munc13 C-terminal C1 and C2 domains. Elife. 2016;5:e13696.

90. Betz A, Okamoto M, Benseler F, Brose N. Direct interaction of the rat unc-13 homologue Munc13-1 with the $\mathrm{N}$ terminus of syntaxin. J Biol Chem. 1997;272(4):2520-2526.

91. Brose N, Hofmann K, Hata Y, Südhof TC. Mammalian homologues of Caenorhabditis elegans unc-13 gene define novel family of C2-domain proteins. J Biol Chem. 1995;270(42):25273-25280. 